Running Head: BLACK MEN'S INITIATIVE

Examining the Impact of a Black Men's Initiative: A Mixed Methods Approach to Program Evaluation

A Dissertation presented to
the Faculty of the Graduate School
at the University of Missouri-Columbia
In Partial Fulfillment
of the Requirements for the Degree
Doctor of Philosophy
JONATHAN FERGUSON
Christopher Slaten, Ph.D., Dissertation Chair

July 2021 
Running Head: BLACK MEN'S INITIATIVE

The undersigned, appointed by the dean of the Graduate School, have examined the dissertation entitled

\section{EXAMINING THE IMPACT OF A BLACK MEN'S INITIATIVE: A MIXED METHODS APPROACH TO PROGRAM EVALUATION}

presented by Jonathan Ferguson,

a candidate for the degree of doctor of philosophy,

and hereby certify that, in their opinion, it is worthy of acceptance.

Associate Professor Christopher Slaten, Ph.D.

Associate Professor Patrick Rottinghaus, Ph.D.

Curators' Distinguished Professor Keith Herman, Ph.D.

Associate Professor Ty-Ron Douglas, Ph.D. 


\section{ACKNOWLEDGMENTS}

I would like to use this space to thank all of those of who have supported me along this journey. Thank you to my committee, for your guidance through this project and throughout the course of my graduate studies. Dr. Rottinghaus, who thought enough of me to interview with a different program before we both began our time at Mizzou, Dr. Herman, who first interviewed me to begin the program and introduced me to my current advisor and to Dr. Douglas who acted as mentor to me for me from a personal and spiritual perspective. A special thank you to my advisor and friend, Dr. Slaten. We started our time at Mizzou together and you have shown me so much over the last six years. You mentored me through the academic, personal, and professional challenges. You protected me when obstacles came my way, and you supported me when I needed it. Thank you.

I must also thank the Division of Inclusion, Diversity, and Equity (IDE). Through IDE I was granted access to professional development that has set a strong foundation as I prepare for the next step in my career. Additionally, I am grateful for the staff at the Gaines-Oldham Black Culture Center for allowing me access to their students, and program materials. Specifically, I want to acknowledge Donald Gilliam and Velma Buckner (affectionately known as Ms. Velma). Ms. Velma and Donald were available and helped me wherever I needed, and I could not have completed this project without them. Finally, I am forever indebted to my amazing participants. I asked a lot of my participants and several saw the project all the way through. Without your voices there is no project and there is no PhD. I simply hope I amplified your voices and told your stories in meaningful manner. 
TABLE OF CONTENTS

ACKNOWLEDGMENTS

iii

LIST OF ILLUSTRATIONS

vi

Abstract

vii

CHAPTER I - Introduction

CHAPTER II - Literature Review

Introduction

Belonging

Black Racial Identity

Black Males in School

Self-Efficacy

The Current Study

Research Questions

CHAPTER III - Method

Participants

Measures

Procedures

Phase I

Phase II

CHAPTER IV - Results

Phase I: Quantitative Analysis

Phase II: Qualitative Analysis

COVID-19 
Access

Identity Development

CHAPTER V - Discussion

Limitations

Implications

REFERENCES

APPENDIX

105

VITA 


\section{LIST OF ILLUSTRATIONS}

Tables

1. Table 1. Within-Group Differences: Interpersonal Variables

2. Table 2. Within-Group Differences: Racial Identity

3. Table 3. Between-Group Difference: Interpersonal Variables

4. Table 4. Between-Group Differences: Racial Identity

5. Table 5. Qualitative Participants

6. Table 6. Qualitative Themes

Additional Material

1. Interview Protocol 


\begin{abstract}
The attrition of Black males in higher education has garnered much attention within recent years. Subsequently, programming specific to this issue has been developed to intervene; however, there is very little research that has captured the impact of such initiatives. The current study employed a mixed methods approach to evaluate the effect a Black men's initiative has on the academic performance, retention, racial identity, sense of belonging, college self-efficacy, and career decision making self-efficacy of Black male college students. Quantitative results for the initiative were inconclusive; however, qualitative interviews reveal that students in the BMI experience different levels of access and identity development than their peers not enrolled in the program. The current study produces implications for future research and academic practice/policy of administrators in higher education.
\end{abstract}




\section{CHAPTER I}

\section{Introduction}

Much has been made about the power of education. Horace Mann (1848) stated "education, then, beyond all other devices of human origin, is the greatest equalizer of the conditions of men." Almost 150 years later, Nelson Mandela (1990) furthered this sentiment by offering that "education is the most powerful weapon which you can use to change the world." While these words from Mann (1848) and Mandela (1990) are inspiring, access education has not always been equal and change is a slow process. As such, the education of Black students has remained an important topic of research for quite some time. Specifically, the education of Black males has rightfully received a lot of attention within recent years (Harper \& Harris, 2012; White House, 2014).

Black men make up approximately $4 \%$ of the college population which is low in comparison to other racial/ethnic groups (NCES, 2016). Additionally, Black male enrollment is also far behind that of their Black female counterparts. Gender differences for Black undergraduates suggest that there are approximately two Black women enrolled in college for every one Black man (NCES, 2016). Despite race or ethnicity, women are generally enrolling in college at higher rates than men; however, the gender disparity for Black students is the largest for any racial/ethnic group. Unfortunately, the barrier for Black men is not just getting into college but persisting as well. After enrolling in college, Black men have one of the lowest completion rates in comparison to their peers with a 6-year graduation rate of $33 \%$ in comparison to the national average of $48 \%$ (Harper \& Harris, 2012). 
Researchers have suggested that Black students in general are more likely to experience feelings of exclusion or ostracism on campus, social isolation, loneliness, in addition to racial dynamics that impact well-being (Betton, 2001; Hurtado \& Ruiz, 2012). Further, literature suggests that Black students are often tasked with balancing work, school, and family life, in addition to reporting a desire for more Black role models, and feeling a lack of support from White faculty and staff (Betton, 2001; Rawlston-Wilson, Saavedra, \& Chauhan, 2014). Black male attrition has been connected to a lower sense of belonging at PWIs, low expectations from professors, gender role conflict, inadequate preparation for college, and low levels of engagement (Bonner \& Bailey, 2006; Harper, 2012; Harris, Palmer, \& Struve, 2011; Strayhorn, 2008).

Researchers have attempted to understand this phenomenon of Black male attrition and suggested counter measures such as leadership positions, student organizations, and even culturally engaging campus environments to increase retention and graduation rates for Black males (Harper, 2009; Harper \& Quaye, 2007; Museus, Yi, \& Saelua, 2018). Harper (2012) suggested that Black male achievement in higher education is associated with peer groups that offer social and academic support and minimize feelings of isolation and exclusion. A small number of colleges across the country have leaned into this line of research recognizing the plight of Black males in higher education and implemented programming designed specifically for Black men (Harper \& Kukendall, 2012; McElderry, Williams, Mayes, Gilliam, \& Taylor, 2018). Despite the increase in programming for Black males, very little research has evaluated the impact of such programs. The current project will evaluate a program specifically designed for Black men enrolled in college at Predominately White Institutions (PWI). 
In providing a rationale for the current study, it is important to briefly capture the context of the historical relationship between Black men and education. It has been argued that Black folks as a whole have been miseducated and misoriented as a result of growing up in a world designed to perpetuate White supremacy (Baldwin, 1984; Cross, 1971; Woodson, 1933). However, many theorists and researchers suggest that while the experiences of Black children and adolescents in educational settings are undoubtedly a product of racist practices, there are a number of experiences that are specific to Black males.

It has been documented that Black boys are disproportionately subjected to phenomena such as overrepresentation in special education (Harry, Klingner, \& Moore, 2000), frequent disciplinary referrals (Adams, Benshoff, \& Harrington, 2007), “niggering” (Harper, 2009), low expectations (Ross \& Jackson, 1991), increased suspensions, and ultimately high dropout rates (Noguera, 2003). In her book, We Real Cool: Black Men and Masculinity, hooks (2004) illustrates the relationship between Black males and education:

More than any group in our society black males are perceived as lacking intellectual skills. Stereotyped via racism and sexism as being more body than mind, black males are far more likely to be affirmed in imperialist whitesupremacist capitalist patriarchy for appearing to be dumb. (p. 33)

Ferguson (2010) extends this argument by suggesting that Black boys receive early messages about the problem with their masculinity in educational spaces and begin to navigate toward spaces where their identities are validated. She argues that as the Black boys are criminalized and over disciplined during school, they seek validation in 
after school sports. This seemingly recreational activity becomes more than a way to keep Black boys, living in poor neighborhoods, out of trouble, and off the streets. She found that after school sport programs become a means for career training and preparation (Ferguson, 2010). Based on her study and the works of others, she argues that Black boys and teenagers begin to receive far more validation during sporting events than during school hours. As such, they begin to see professional sports as a practical career option and foreclose on alternatives that involve formal education (Beamon, 2010; Ferguson, 2010). Thus, Black males are less likely to pursue higher education than other groups. Those that persist through the P-12 education system and enroll in college face a new set of challenges, particularly when enrolling at a PWI (Bonner \& Bailey, 2006; Harper, 2012; Harris, Palmer, \& Struve, 2011; Strayhorn, 2008).

Once on college campuses, Black men are still subjected to negative experiences such as low expectations, low levels of engagement, a lowered sense of belonging that ultimately lead to high rates of attrition (Bonner \& Bailey, 2006; Harper, 20009; Harper \& Harris, 2012; Harris, Palmer, \& Struve, 2011; Strayhorn, 2008). In order to address these concerns, researchers and universities across the United States have made attempts at designing programs aimed to increase Black male retention (Harper \& Kukendall, 2012; Lavant, Anderson, \& Tiggs, 1997; McElderry et al., 2018).

Many of the programs developed captured the significance of mentor relationships which has been researched at length within the Black community (Butler, Evans, Brooks, Williams, \& Bailey, 2013; Gordon, Iwamoto, Ward, Potts, \& Boyd, 2009; Harvey \& Hill, 2004; Jones, Holton, \& Joseph, 2019; Lavant, Anderson, \& Tiggs, 1997; Roberts-Douglas \& Curtis-Boles, 2013). Mentoring within the context of higher 
education has been associated with persistence, perceived support, and satisfaction with college; however, studies have presented mixed results about the impact on academic achievement which suggest that mentoring is not enough (Brittian, Sy, \& Stokes, 2009; Palmer \& Gasman, 2008; Strayhorn \& Saddler, 2009; Strayhorn \& Terrell, 2007).

In their conceptual paper, McElderry and colleagues (2018) describe a program based on the theoretical framework of belonging (Strayhorn, 2019) and Black identity development (Cross, 1995) that includes mentoring but aims to "effectively assist firstyear Black males in their transition into the [university] collegiate environment” (p. 33). The theoretical foundation of belongingness and Black racial identity development is key because both constructs have been related to the success of college students (Chavous, et al., 2003; Pittman \& Richmond, 2007; 2008).

Within collegiate settings, belonging has been positively associated with constructs like psychological adjustment, motivation, and grade point average (Guiffrida, Lynch, Wall, \& Abel, 2013; Pittman \& Richmond, 2007; 2008). When considering the relevance for Black men specifically, belonging has been related to college adjustment, academic performance, involvement on campus and college satisfaction (Strayhorn, 2019; Strayhorn \& Mullins, 2012). Racial identity has been positively related to variables like self-esteem, academic performance, intention to persist to graduation, psychological well-being, and self-efficacy (Chavous et al., 2003; Gushue, 2006; Pillay, 2005; Rowley, Sellers, Chavous, \& Smith, 1998).

The Black men's initiative to be evaluated by the current study is based upon a two-semester course that is guided by three identified pillars of support, development, and involvement (McElderry et al., 2018). The initiative is positioned on the campus of 
The University of Missouri and includes mentoring, presentations and discussions with Black male faculty and graduate students, leadership training, participation in service programs, and involvement in student organizations.

While it is generally accepted that programming to address Black male attrition is important and warranted, there is very little research that has evaluated the effectiveness of initiatives such as the one described by McElderry and colleagues (2018). This dissertation will add to this body of literature by evaluating the effect these interventions have on the academic performance, retention, sense of belonging, and identity development of Black male college students. This project will employ an explanatory mixed methods approach to evaluate programming designed using the guidelines identified by McElderry and colleagues (2018) to increase retention in Black males at a large research institution in the midwestern region of the United States.

Results of this study add to an existing body of literature regarding Black males in higher education. It can be used to identify barriers to collegiate success for Black men while also identifying areas of strength. In addition, the current project will also inform literature specific to intervention. As previously mentioned, there is very little literature that evaluates the impact of Black male initiatives in higher education. This project will add both quantitative analysis and qualitative data about the effect of the program. The quantitative results will provide insights about the appropriate theoretical approach to intervention and increase our understanding of such interventions can impact retention and achievement while fostering belonging and racial identity development. The qualitative results will provide insight to the experience Black males have on college campuses and as members of specific programs. In addition, the qualitative data may 
provide information about specific parts of the intervention that were impactful (e.g., peer support, involvement on campus, contact with faculty, etc.) or not impactful. Overall, this study will produce significant implications for University administrators and program directors that can be used to recruit, retain, and graduate Black male students. 


\section{CHAPTER II}

\section{Literature Review}

This chapter will provide context to the current study by reviewing literature relevant to the Black men's initiative that is to be examined (McElderry, et al., 2018). Specifically, this literature review will expand upon the theoretical foundation of belongingness (Baumeister \& Leary, 1995; Maslow, 1954; Strayhorn, 2019) and Black racial identity development (Cross, 1995). In addition, this chapter will review empirical studies that have tested these theories and identified significant relationships with constructs such as academic performance (Chavous, et al., 2003; Pittman \& Richmond, 2007; 2008), retention (Chavous, et al., 2003; Strayhorn, 2019), and self-efficacy (Freeman, Anderman, \& Jensen, 2007; Gushue, 2006).

\section{Belongingness}

First presented by Maslow $(1943 ; 1954)$, belongingness is a construct rooted deeply in the history of psychology. In his seminal work, Maslow (1954) presented a theory of human motivation entitled Hierarchy of Needs. Within this theory, Maslow (1954) defines belonging as the connections gained through the establishment of genuine relationships. Additionally, he suggests the need for love and belonging, along with four other basic needs, are fundamental to human motivation. Further, he theorized that belonging was not just fundamental to human motivation but rather a powerful need for human beings to satisfy only after satisfying physiological (i.e. food, water, oxygen) and safety (i.e. shelter) needs. Given the power of this construct, Maslow's (1954) foundational work inspired a significant body of literature related to the construct of belonging (e.g., Baumeister \& Leary, 1995; Bronfenbrenner, 1977). 
The Belongingness Hypothesis. Extending Maslow’s (1954) work, Baumeister and Leary (1995) presented the Belongingness Hypothesis, where they also identify belongingness as a fundamental human motivation and need; however, they expanded the definition of belonging and the depth of its impact. Baumeister and Leary (1995) define belonging as "a need to form and maintain at least a minimum quantity of interpersonal relationships" (p.499). They expanded the theoretical understanding of belonging by suggesting that the construct can be characterized by two main features: frequent personal contact with others and the need to perceive a stable, ongoing relationship.

While Baumeister and Leary (1995) agree that the need to belong is innate they expand this idea to argue that belonging is not just an innate desire but also a need based in evolution for the purposes of human survival. They suggest that belonging provided means for protection, reproduction, shared resources, and ultimately affection. Within modern context, they suggest that belonging drives motivation and goal-directed action while its absence results in adverse reactions such as distress or pathology (both physiological and psychological).

Within the Belongingness Hypothesis, Baumeister and Leary (1995) also distinguished belonging as a unique construct that stood apart from similar terms like affiliation and social support. They suggest that belonging requires a depth in social connection that is not captured by either term. Specifically, they cite a level of reciprocity that is needed for one to perceive a sense of belonging whereas reciprocity is not necessary for one to feel a sense of affiliation or membership. Similarly, social support can be shown in frequent interactions and even actions that communicate support for an 
individual in one form or another; however, the act of support does not always communicate the level of care associated with a sense of belonging.

The essence of Baumeister and Leary's (1995) hypothesis was to illustrate the depth of belongingness as a need fundamental to the well-being of an individual. They communicated this by describing belonging as an innate human need for genuine, social connection and interpersonal relationships with others. Baumeister and Leary (1995) took this idea a step further with the claim that belonging can be satiated. Thus, suggesting that if one feels a sense of belonging within any domain of their life, the need for belonging has been satisfied and increases the chance of feeling a sense of belonging in other areas. This claim suggests that there are multiple levels where individuals can establish genuine relationships and thus satisfy their need to belong.

Baumeister and Leary's (1995) claim of satiation is consistent with ecological models of human development (Allen, Vella-Brodrick, \& Waters, 2016; Bronfenbrenner, 1979). Such theories suggest that child development is fostered by their sense of belonging to different levels of society (i.e., microsystem, mesosystem, exosystem, and macrosystem). As a result, much research has been conducted with consideration to the experience of belonging specific to educational spaces (Slaten, Ferguson, Allen, VellaBrodrick, \& Walters, 2016).

\section{School Belonging}

Within recent decades, researchers have become increasingly interested in the construct of school belonging (Slaten, et al., 2016). Many have offered definitions of school belonging (Ma, 2003, Willms, 2000); however, Goodenow and Grady (1993) offer the most widely used definition. They defined school belonging as "the extent to which 
students feel personally accepted, respected, included and supported by others in the school social environment" (Goodenow \& Grady, 1993, p. 80).

School belonging has been related to a number of variables such as extracurricular activities (Dotterer, McHale, \& Crouter, 2007; Shochet, Smyth, \& Homel, 2007), academic motivation, (Anderman, 2003; Whitlock, 2006), mental health (Holt \& Espelage, 2003; Shochet, Smith, Furlong, \& Homel, 2011), gender (Ma, 2003; Sanchez, Col’on, \& Esparza, 2005), and race and ethnicity (Bonny et al., 2000). In addition, literature suggests a positive relationship between school belonging and perceived support from others: peer support, teacher support, and parent support (Garcia-Reid, 2007; Hallinan, 2008; Wang \& Eccles, 2012).

Baumeister and Leary (1995) suggested that the absence of belonging would lead to pathology and researchers have developed a relationship between school belonging and mental health (McMahon, Parnes, Keys, \& Viola, 2008; Moody \& Bearman, 2004; Shochet, Smyth, \& Homel, 2007). Newman, Newman, Griffen, O’Connor, and Spas (2007) found a significant inverse relationship between school belonging and depressive symptoms. They found that during transition from middle school to high school students' sense of school belonging tends to decrease and therefore depressive symptoms increase (Newman, et al., 2007). Not only are their findings supportive evidence for Baumeister and Leary's (1995) theoretical hypothesis but their findings also suggest that belongingness declines during transition.

Shochet, Smith, Furlong, and Homel's (2011) study of school belonging and psychological factors investigated the impact of school belonging on negative affect in adolescent students. Using the Psychological Sense of School Membership Scale (PSSM) 
(Goodenow \& Grady, 1993) and the Children’s Depression Inventory (CDI) (Kovacs, 1992), researchers surveyed 504 seventh and eighth grade students in Australia.

Researchers found that school belonging was a significant predictor of negative affect in adolescents (Shochet, et al., 2011).

As researchers continuously find evidence to support belongingness as legitimate need (Newman, et al., 2007; Shochet, et al., 2011), others have furthered this idea by studying both how a lack of belonging may hinder students but also how a healthy sense of belonging impacts students positively. Anderman (2002) examined the relationship between school belonging and psychological outcomes using a large sample of students $(\mathrm{N}=20,745)$ from schools across the United States $(\mathrm{N}=132)$. The researcher selected measurements of school belongingness, school problems, social rejection, optimism, selfconcept, and depression. School belonging was found to be negatively correlated with depression, social rejection, and school problems which is consistent with ideas presented in similar studies (Newman, et al., 2007; Shochet, 2011). However, Anderman's (2002) study also indicated a positive correlation between aggregated school belonging and Grade Point Average (GPA), social rejection, and school problems. These results suggest that the more students feel a collective sense of school belonging the more rejection those students on the outside feel and the more problems they will encounter (Anderman, 2002).

School belongingness has shown to be a strong predictor of motivation, academic performance, and negative emotions (Goodenow \& Grady, 1993; Anderman, 1999). Further, school belonging has been shown to support adjustment, transition as well as dropout prevention (Kuperminc, Dranell, \& Jimenez, 2008; Pittman \& Richmond, 2007; 
Slaten, Elison, Hughes, Yough \& Shemwell, 2015). Slaten and colleagues (2015) conducted a qualitative study to understand the educational needs of adolescents enrolled at an alternative high school in the Midwest region of the United States. They completed interviews and analyzed the data to identify several themes that emerged from the data. Participants cited sense of belonging in school as one of the most salient themes and noted that genuine relationships with teachers/administrators was a significant part of belonging. Students identified school belonging in the form of relationships with school faculty as a primary motivation to stay in school as opposed to dropping out (Slaten, et al., 2015).

In addition to research that has linked school belonging with positive outcomes for students (Anderman, 1999; Goodenow \& Grady, 1993; Kuperminc, et al., 2008; Pittman \& Richmond, 2007; Slaten, et al., 2015), researchers have also identified factors that influence belonging (Allen, Kern, Vella-Brodrick, Hattie, \& Waters, 2018). Allen and colleagues (2018) conducted a meta-analysis to identify factors that foster a sense of school belonging. Researchers identified ten themes based on a bioecological model of school belonging (Allen, et al., 2016): academic motivation, positive and negative personal characteristics, gender, race/ethnicity, parent, peer, and teacher support, extracurricular opportunities, and environmental/school safety. The initial wide search criteria included forty-five key search terms related to school belonging and influencing yielded 623 studies published between 2002 and 2012. Studies were then excluded based on specific inclusion criteria: participants between ages of 12 and 18, data collection in secondary schools, quantitative study, variables relevant to at least one of the ten themes previously identified, school belonging defined the same way as Goodenow and Grady 
(1993), school belonging as dependent variable, school belonging measured by more than one item, and a reported effect size (Pearson r). These criteria plus the exclusion of studies with missing data or deficient measures reduced the collection of studies to a total of 51. Their study found a significant relationship across all themes except race. ethnicity and extracurricular activities. The largest effect was found for teacher support and personal characteristics. Allen and colleagues (2018) suggest that their findings can be used to inform interventions to foster belonging at the K-12 level.

\section{School Belonging in Higher Education}

As previously mentioned, belonging is a construct that manifests across various groups and settings. Within recent decades school belonging researchers have begun to focus their efforts on understanding the experience of belonging for young adults in collegiate settings (Slaten, et al., 2014). Within higher education, research has shown belonging to be associated with psychological adjustment, motivation, and grade point average (Pittman \& Richmond, 2007; Pittman \& Richmond, 2008; Guiffrida, Lynch, Wall, \& Abel, 2013). Researchers have made past attempts to develop theory specific to the experience of belonging on college campuses (Tinto, 1988); however, within recent years new models with culturally relevant considerations have been called for and created (Guiffrida, 2006; Museus, 2014; Strayhorn, 2019; Tierney, 1992).

Without being explicitly stated, research on school belonging within college student populations began decades ago. Tinto, (1988) suggested that belonging was a significant part of a student's transition from high school to college. He theoretically related the retention of college students to the extent to which one can separate old associations and develop new relationships at the collegiate level. Tinto (1988) referred 
to the process as a rite of passage and identified three stages: separation, transition, and incorporation. During the stage of separation, students' relationships change and they are forced to either disengage or disconnect from previous communities. During the transition stage, he described students as stuck between their home and collegiate communities. They left their previous communities but have not yet formed new relationships to establish a new community within the collegiate setting. Tinto (1988) suggests that students are highly stressed during this stage and may withdraw without support. The last stage of incorporation was described as the stage when students have learned the norms of college and become integrated into the culture. At this stage he suggested that students attain membership and subsequently a sense of belonging. Tinto's (1988) work was significant to the study of belonging because it suggested that the absence of belonging was detrimental to their ability to persist. Despite this contribution, others have taken issue with Tinto's (1988) theory.

In attempt to adequately research this growing body of work, researchers have made attempts at identifying predictors of school belonging that are specific to college populations (Freeman, Anderman, \& Jensen, 2007; Guiffrida, et al., 2013; Slaten, et al., 2014). Freeman and colleagues (2007) evaluated college students' sense of school belonging within the classroom and the university as a whole. They attempted to examine the relationships between school belonging, academic motivation, and instructor characteristics. Data were collected from a sample of college freshmen $(\mathrm{N}=238)$ and the results indicated that social acceptance and pedagogical concern of instructors were large predictors of school belonging on a college campus. 
Research has suggested that school belonging in higher education may be related to academic performance, but it is not necessarily related to college students' persistence to graduation (Guiffrida, et al., 2013). A study by Guiffrida and colleagues (2013) provided evidence for this distinction, noting that high achieving students are not always motivated to finish college. The study examined the relationship between GPA, intention to persist and motivation. A large sample of college students $(\mathrm{N}=2,520)$ were asked to complete questionnaires including measures of competence, motivation, autonomy motivation, need for relatedness, intent to persist, and GPA along with demographic information (SES, race/ethnicity, gender, and 2 or 4-year institution). After analyzing the data researchers determined there was a significant relationship between relatedness and GPA. With regard to students' intention to persist only the measure of relatedness to school faculty was shown to have a significant relationship. The results lacked support for the other measures of relatedness (relatedness to home-altruistic, relatedness to homekeep up, and relatedness to school/ peers). Guiffrida and colleagues (2013), paper suggests that relation to faculty is the most important factor in retention of college students. This study provides minimal support for Tinto's (1988) theory by suggesting that students are more likely to persist if they feel related to a representative of their college; however, Guiffrida and colleagues (2013) study does not suggest that students need to become fully integrated through peer relations and school affiliation.

Slaten and colleagues (2014) employed a Consensual Qualitative Research (CQR; Hill, 2012) design in order to understand the experience of belonging for students in a college setting. Through this inquiry, researchers were able to identify several domains related to university belongingness: valued group involvement, meaningful personal 
relationships, environmental factors, and interpersonal factors. With this study, Slaten and colleagues (2014) determined that school belongingness looks different at the university level than at the school age level. The results found by Slaten et al. (2014) do not disprove Tinto's (1988) theory nor does it disprove the results found by previous studies (Pittman \& Richmond, 2007; Pittman \& Richmond, 2008; Guiffrida, et al., 2013). However, the results suggest that belonging at the collegiate level is multifaceted and may be more complex than Tinto's (1988) theory suggested.

Due to the fact that school belonging at the collegiate level is still a growing area of research there are opportunities for future research to be completed. As work by Slaten and colleagues (2014) suggests, school belonging looks different for students enrolled at a 2-4 year college than it does for students enrolled at a local K-12 schools and there are many different variables that could be researched within this topic. In fact, there is a growing desire for school belonging work that is culturally sensitive and/or specific (Guiffrida, 2006; Tierney, 1992).

\section{Culturally Specific Belonging in Higher Education}

Some researchers have taken issue with Tinto's (1988) theory of student departure, citing that his work is individualistic in nature and does not account for difference in experience based on race or class (Tierney, 1992). Tierney (1992) asserts that Tinto's (1988) idea that students need to break associations with prior relationships and/or communities is reflective of a Eurocentric worldview. As a result, Tierney (1992) suggests that Tinto's (1988) theory does not provide an appropriate framework to understand the experience of minority students and argues for more culturally relevant models of belonging for college students. 
Guiffrida (2006) would eventually adapt Tinto's (1988) theory to include a broader look at belonging that incorporates the impact of culture on students' experience. He asserts that a theory on the transition of students into college must recognize the impact of students' previous communities and take on more of an acculturative perspective as opposed to the assimilation model. In addition, he argues for the inclusion of Self-Determination Theory (SDT; Deci \& Ryan, 1985) of motivation and Job Involvement Theory (JIT; Kunungo, 1982). Guiffrida (2006), suggests that SDT would inform students' experience of both intrinsic and extrinsic motivation that helps them persist to graduation while JIT informs the impact of cultural norms on motivation of students from both individualistic and collectivist cultures. In sum, Guiffrida (2006) suggests that Tinto's theory (1988) would be more applicable to minority students by including an inherent value for family and cultural connections while also valuing the relationship between cultural norms and motivation to achieve and persist academically.

While Guiffrida (2006) adapted Tinto's (1988) model, other scholars suggested new models altogether (Museus, 2014; Strayhorn, 2019). Museus (2014) presented the theory Culturally Engaging Campus Environments (CECE) as a model to promote success for ethnic minority students in higher education. The model was derived from critiques of previous theories (Guiffrida, 2006; Tierney, 1992; Tinto, 1988) and previous research studying the spaces where ethnic minorities were achieving (Museus, 2011). In this model it is theorized that student success is influenced by external influences (i.e., finances, family, employment), pre-college inputs (initial academic disposition, initial academic performance, demographic information), individual influences (i.e., sense of belonging, academic disposition, and academic performance), and culturally engaging 
campus environments. He identifies nine indicators of culturally engaging campus environments that influence college student success: cultural familiarity, culturally relevant knowledge, cultural community service, opportunities for meaningful crosscultural engagement, collectivist cultural orientations, culturally validating environments, humanized educational environments, proactive philosophies, availability of holistic support.

The focal point of the theory, and the point most salient to the current study, is the interaction between culturally engaging campus environments and individual influences. Museus (2014) suggests that culturally engaging campus environments are positively related to individual influences such as sense of belonging and academic performance. There has been much research to corroborate this theory (Kiyanna, Museus, \& Vega, 2015; Museus, 2008; Museus, Yi, \& Saelua, 2017).

Recently, Museus, Yi, and Saelua (2017) evaluated the relationship between culturally engaging campus environments and sense of belonging. Researchers distributed a survey to 499 college students across 3 campuses. One campus was a 4-year research institution located on the East Coast of the United States while the other two were community colleges located in rural areas on the West Coast of the United States. The sample was $75 \%$ female but racially diverse, including students from various backgrounds: White (27\%), Asian American (25\%), Pacific Islander (9\%), Multiracial (9\%), Latino (8\%), Black, (5\%), Native American (2\%), and others (15\%). The survey included a demographic questionnaire in addition to 54-items designed to assess the nine indicators of culturally engaging campus environments mentioned above and 3-items to assess sense of belonging. It is important to note that this measure of belonging is 
relatively weak. While the internal consistency is strong (Cronbach alpha $=.97)$, the items don't quite capture the complexity of belonging at the collegiate level as highlighted by Slaten and colleagues (2014). Despite this limitation, their results indicated a positive relationship between sense of belonging and all of the indicators of culturally engaging campus environments except one (cultural community service). Further, they found this relationship was present for students of color and White students as well. This study highlights the significance of culturally specific methods of fostering belonging while also indicating that culturally specific practices is related to a greater sense of belonging for ALL students and not only students of color.

Strayhorn (2019) furthered this notion by developing a theory of belonging for college students that explicitly addresses the impact of social identity. In his theory he identifies seven core elements of belonging. The first acknowledges that belonging is a basic human need as derived from Maslow's (1954) Hierarchy of Needs. Second, belonging is not only a basic human need but also a motive to drive behavior. Third, belonging becomes increasingly important in certain contexts, at certain times, and for certain groups. This element is of significance to the current project because Strayhorn (2019) relates this to transitional periods, such as the experience of starting college for the first time. The fourth element suggests that belonging is related to and/or results from mattering. Next, Strayhorn (2019) suggests that belonging is impacted by the intersection of social identities. This will also be discussed further, as it is of particular importance to the current study. The sixth core element asserts that belonging is related to positive outcomes for college students and the last suggests that belonging changes with circumstance but must be satisfied on a continual basis. 
While many of the elements outlined by Strayhorn (2019) have been addressed in this review of relevant literature, elements such as the contextual nature of belonging and its relationship with intersecting identities were explored further. Belonging becoming more important at different times is an important element for the current project because the intervention is designed for first-year students. Researchers have theorized and tested the notion that belonging is of increased importance for students during this transition from high school to college (Hausmann, Schofield, \& Woods, 2007; Hausmann, Ye, Schofield, \& Woods, 2009; Hoffman, Richmond, Morrow, \& Salomone, 2002; Museus, 2014; Pittman \& Richmond, 2008; Tinto, 1988). A significant study was conducted by Hausmann and colleagues (2009) where they evaluated the impact a simple intervention would have on the sense of belonging in Black and White first-year students. Their sample included 356 first-year, non-transfer students at a four-year university located in the Mid-Atlantic region of the United States. Of the 356 participants, $60 \%$ were White and $59 \%$ were female. Participants were randomly assigned to either a control group or the experimental group which received the intervention. Participants in the intervention group received written communication from university of administrators indicating that the students were valued members of the collegiate community. In addition, students in the experimental group received small gifts from the university throughout the academic year (e.g., t-shirt, caps, ID holders, etc.). After analyzing the data, researchers found that sense of belonging was significantly related to intention to persist for all participants. This finding highlights the importance of belonging during this transition (Strayhorn, 2019). Additional findings for Hausmann and colleagues (2009) suggested that belonging was significantly higher for White students who received the intervention as opposed to 
those in the control group; however, this same effect was not observed for Black students. Hausmann and colleagues (2009) acknowledged that their intervention lacked cultural influences which is theorized as an important aspect of Strayhorn's (2019) model.

While many studies have attempted to understand the impact of race as it relates to the sense of belonging students feel in academic settings (P-12 or higher education), there is minimal literature that connects belonging to racial identity development. The current study will attempt to illuminate this relationship as McElderry and colleagues (2018) identify belonging and racial identity development as the main theoretical influences of the intervention.

\section{Black Racial Identity}

The topic of social identity is both a complex and emotional topic for many. Much of our experience is based upon how we view and position ourselves in the world but also how others position us (Kirk \& Okazawa-Rey, 2006). While it is accepted that human beings are an intersection of multiple, socially constructed identities, the current study will focus on the construct of race within the context of the United States. Specifically, the current paper will explore theories about Black racial identity development.

Many scholars have studied Black identity development (Baldwin, 1981; Baldwin, 1984; Cross, 1971; Cross, 1995; Kambon, 2006; Nobles, 1973). Of these, Cross's (1971) model of Nigrescence, is the most widely used and accepted.

Nigrescence. This model suggests that people who identify as Black move through several stages along their identity development until they have reached a place of congruence and confidence in their identity as Black (Cross, 1971, 1995; Vandiver, 
2001). Specifically, the model outlines four stages in which Black people navigate in a nonlinear fashion: (1) Pre-encounter, (2) Encounter, (3) Immersion/Emersion, and (4) Internalization

Pre-Encounter. The pre-encounter stage is described as the period before Black people begin to understand racism. In the revised model Cross and Vandiver (2001) suggests that this stage has three specific identity clusters. The first being pre-encounter assimilation, where individuals strive to be accepted and see themselves as a part of the dominant culture. An example of this would be a Black person who identifies themselves by saying “I'm not Black, I'm just American.” Next, the pre-encounter miseducation cluster where people internalize negative ideas about Blackness. Individuals in this cluster see the world as it was prescribed to them through mainstream media and formal education systems that perpetuate negative stereotypes. Last, is the pre-encounter selfhatred cluster where individuals have not only internalized negative ideas of Blackness but are actively attempting to distance themselves from Blackness (e.g., bleaching skin, engaging in anti-Black rhetoric). Overall, individuals in the pre-encounter stage have yet to adopt a critical lens that questions ideas of Black inferiority and instead they internalize ideas of self-hate and seek to see themselves as members of the dominant society.

Encounter. The next stage is the encounter stage, when individuals come in contact with racism and begin to question racist ideologies for the first time. This stage has been described as merely transitional because it serves as the awakening point where one realizes that racism exists and it sparks their interest to explore their own racial 
identity. As a result of its transitional nature, researchers have had difficulty measuring this stage (Cokley, 2002; Cross \& Vandiver, 2001).

Immersion/Emersion. This stage is characterized as a pro-Black attitude;

however, it described as a radicalized Blackness. In this stage the individual still maintains dichotomous thinking held in the pre-encounter stage, only the focus is now pro Black as opposed to anti-Black. Cross developed two identity clusters within this stage of development: intense Black involvement and anti-White. The immersion/emersion intense Black identity celebrates and seeks Blackness. Cross (1995) suggests that this identity type believes everything Black is good. The immersion/emersion anti-White identity type views Whiteness as negative and/or evil.

Internalization. In this stage, the individual has moved through the radical ideas of Blackness as well as the dichotomous thinking of either Black or White, and they have now reached a place of self-acceptance. Within this stage are three identity types: Black Nationalist, Biculturalist, and Multiculturalist. While all of these identities are characterized by a general sense of acceptance, the identities are separated by the number of social identities accepted beyond their Black identity. The Black nationalist identity suggests that the individual has accepted their Black identity and engage in some sort of activism/advocacy for the Black community. Biculturalist identity suggests the individual positions and integrates themselves within two salient identities. Vandiver (2001) uses the example of Black and American to illustrate the biculturalist identity. The multiculturalist identity suggests that an individual accepts three or more salient social identities and operates within the cultural framework of each identity. 
Though widely accepted by the field of psychology, Cross's $(1971,1995)$ model also met some resistance. Some Black scholars criticized the framework and introduced competing ideas of Black identity (Baldwin, 1984; Kambon, 2012; Nobles, 1976).

Criticism of Nigrescence Model. Among the scholars criticizing Cross's (1971, 1995) model, were Na’im Akbar (1989), Kobi Kambon (2012) (formerly known as Joseph Baldwin (1981; 1984)), and Wade Nobles (1976). Each of these scholars identified as African-Centered psychologists and were intricate pieces of the Association of Black Psychologists' (ABPsi) African-Centered Psychology movement (as was Cross). Both Kambon (2012) and Nobles (1976) argued that Cross's model of Nigrescence was developed using a Eurocentric worldview. In fact, Kambon (2012) referred to the theory as "Pseudo-Africentric," suggesting that it was developed by a person of Africandescent,but did not employ an African-Centered worldview.

Akbar (1989) lays out several critiques of Cross's (1971) original theory: (1) the model did not acknowledge African identity as the core of Black identity, (2) racial identity is considered a role component among other components as opposed to the core component, (3) the immersion stage is conceptualized as a reactive condition as opposed to a natural process of healthy development, and (4) that security with Black racial identity is determined by how comfortable they feel relating to people of other racial/ethnic groups. Other scholars have critiqued the model by suggesting that it is reactive to negative experiences as opposed to an affirmative process of one's identity (Kambon, 2012).

Along with criticism of Cross's (1971; 1995) model Nobles (1976) and Kambon (Baldwin, 1981; 1984) offered their own models of Black identity. Nobles (1976) model 
defines Black identity as the African self-concept. Subscribing to an African worldview that values community orientation and survival of the group, Nobles (1976), asserts that the African self is defined by "the WE instead of the I" (p. 20). Thus, he argues that the Black identity is predicated on the simultaneous identification and denial of qualities and characteristics that are either similar or different to that of one's own qualities and characteristics. Similarly, Kambon's (Baldwin, 1981; 1984) model of African SelfConsciousness (ASC) is based on an African worldview. He argues that the ASC is both genetic and environmental in nature. Thus, he theorized that Black folks are born with a natural African Self-consciousness; however, our interactions and education about the world from a western worldview leaves us "culturally misoriented" (Kambon, 2012, p.97). The ASC is characterized by a recognition of oneself as African, recognition of African survival, perpetuation of African life and institutions, and an active defense toward all things non or anti-African (Baldwin, 1981). Despite criticisms about Cross's (1971; 1995) model and alternative theories of Black identity (Baldwin, 1981; 1984; Nobles, 1976), Nigrescence has garnered the most attention and evidence (Cokley, 2002, 2005; Vandiver \& Cross, 2001).

Cokley (2002), conducted a study that tested Cross's (1995) model by examining the relationship between racial identity and internalized racism in 153 Black students. Cokley (2002) used the Cross Racial Identity Scale (CRIS; Vandiver, Cross, Worrell, \& Fhagen-Smith, 2002) to measure racial identity and the Nandanolitization (NAD; Taylor \& Grundy, 1996) to assess internalized racism. His study found support for the Nigrescence model, suggesting that pre-encounter stages were related to internalized stereotypes of African Americans such as natural abilities and mental and genetic 
deficiencies, immersion-emersion stage was significantly related to beliefs about sexual prowess of African Americans, and the internalization stage was significantly related to belief in natural abilities of Blacks (e.g., belief that Black people are naturally better dancers than White people).

In addition to empirical support for Cross's (1995) theory, the Nigresence model is of significance to the current study because it is employed in the design of the intervention being evaluated for the current study. McElderry and colleagues (2018) suggest that it is the aim of the intervention to foster growth along racial identity as it relates to the Nigrescence (Cross, 1995) model and increase feelings of belongingness to foster the retention of Black men. Previous studies have suggested that racial identity is positively related to self-esteem, academic performance and attainment (i.e., the desire to persist to graduation and further) and psychological well-being (Chavous, et al., 2003; Pillay, 2005; Rowley, et al., 1998). Additionally, studies have identified racial identity as a positive predictor of self-efficacy (Gushue, 2006; Reid, 2013; Smith, Walker, Fields, Brookins, \& Seay, 1999; Witherspoon, Speight, \& Thomas, 1997).

\section{Black Males in Schools}

As previously alluded to, Black males encounter significant challenges throughout their experience in the school system. From the time young Black boys enter preschools they are over disciplined, under supported, and either funneled into special education or out of schools all together (Adams, Benshoff, \& Harrington, 2007; Harry, Klingner, \& Moore, 2000; Harper, 2009; Noguera, 2003; Howard, 2014; Ross \& Jackson, 1991). Ladson-Billings (2011) asserts that society has a love-hate relationship with Black males where they are suggested to be the basis for many societal issues, yet they are praised in 
certain spaces such as sport and music. Ferguson (2010) suggests that Black boys are essentially pushed out of educational spaces because their identities are problematized, yet they receive an abundance of praise on athletic fields. These are only a few examples of ways in which the identities of Black males are seen as troubling or unfit for certain spaces.

Howard (2014) identifies five popular depictions of Black males that have presented issues within schools and society at large: (1) the physical brute and antiintellectual, (2) shiftless and lazy, (3) hypersexual, (4) criminal minded, and (5) slickster pimp/gangster. He suggests that these depictions have contributed significantly to the detriment of Black male well-being. Within the context of schooling, researchers have cited issues of racism, cultural norms, and mix between the two (Nogura, 2003; Ogbu, 1987; Wilson, 2008). Unfortunately, scholars have suggested that these issues are not limited to the PK-12 level of education (Harper, 2012; Harper \& Harris, 2012).

Black Male College Students. At the collegiate level Black men continue to face many of the same obstacles presented throughout their educational matriculation such as low expectations, low levels of engagement, a lowered sense of belonging that ultimately lead to high rates of attrition (Bonner \& Bailey, 2006; Harper, 20009; Harper \& Harris, 2012; Harris, Palmer, \& Struve, 2011; Strayhorn, 2008). Additionally, Black male college students experience an erasure of within group difference among them and are remarginalized by well-intentioned initiatives that treat the experience of Black male students as monolithic (Harper, 2014). Amechi and colleagues (2016) explore several subgroups of Black men that often have vastly different experiences on college campuses: gay, bisexual, or queer (GBQ) men, men in historically Black fraternities, 
student athletes, students at Historically Black Colleges and Universities (HBCUs), underprepared, disengaged low performers, and college achievers and student leaders. These groupings are salient because these groups experience different challenges and thus are faced with different outcomes (Harper, 2015; Harper, Williams, \& Blackman, 2013; Strayhorn, Blakewood, \& DeVita, 2008).

Of particular significance to the current study is work completed by Harper and Quaye (2007). They sought to the experience of high-achieving Black men who held leadership positions across their respective campuses. The study included 32 participants from six PWI universities who were identified as high-achieving, student leaders. Harper and Quaye's (2007) findings suggest that involvement in student organizations, predominantly Black or White, allowed students the space for Black expression and skill development. These findings are relevant to the current study as the BMI being evaluated not only promotes student involvement but also operates as its own student organization (McElderry, et al., 2018

\section{Self-Efficacy}

Identified as a key theoretical component of Bandura's (1989) social cognitive theory, self-efficacy has historically been viewed as central to the learning process of human beings. Self-efficacy is defined as “people's beliefs about their capabilities to produce designated levels of performance that exercise influence over events that affect their lives" (Bandura, 1994, p. 1). Bandura (1977; 1989; 1994) suggests that self-efficacy is related to both performance outcomes and persistence. Given its generalizability, selfefficacy has been studied across a wide range of literature such as exercise, internet use, physical health, mental health, teaching, and academics (Barz, et al., 2016; Buck, et al., 
2015; Gangadharbatla, 2008; Roth, Westrheim, Jones, \& Manger, 2017; Schwarzer \& Renner, 2000; Skaalvik \& Skaalvik, 2016; Soysa \& Wilcomb, 2015). The current study will focus on self-efficacy as it relates to both college related tasks and career decision making (Hackett \& Betz, 1981; Solberg, O’Brien, Villareal, Kennel, \& Davis, 1993; Taylor \& Betz, 1983).

College Self Efficacy. Many researchers have studied self-efficacy within the context of higher education. Studies have found self-efficacy to be positively related to a plethora of variables such as academic performance, academic adjustment, goal orientation, purpose in life, and retention (Chemers, Hu, \& Gracia, 2001; Choi, 2005; DeWitz, Woolsey, \& Walsh, 2009; Hseih, Sullivan, \& Guerra, 2007). A classic metaanalysis conducted by Multon, Brown, and Lent (1991) on self-efficacy and its relationship with academic performance and persistence. Their results suggested that selfefficacy accounted for a significant amount of the variance in both academic performance and persistence.

Study of self-efficacy within higher education shifted when Solberg and colleagues (1993) introduced a nuanced way of studying the construct amongst college students. They presented a scale to measure college self-efficacy as its own construct. It was operationally defined as the "a student's degree of confidence that they could successfully complete a given college related task" (Solberg, et al., 1993, p. 80). In other words, college self-efficacy was not simply students' general belief in themselves but rather their specific beliefs about their ability to be successful in college. College selfefficacy as an independent construct has been related to intention to persist, college adjustment, academic performance, life satisfaction and college satisfaction (Baier, 
Markman, \& Pernice-Duca, 2016; Coffman \& Gilligan, 2002; DeWitz \& Walsh, 2002;

Ramos-Sanchez \& Nichols, 2011; Vuong, Brown-Welty, \& Tracz, 2010).

Of particular importance to the current project was a study conducted by

DeFreitas and Bravo (2012). They examined the influence of mentoring and involvement with faculty on the academic achievement and self-efficacy of Black and Latinx students attending an Hispanic Serving Institution (HSI). It is important to note that there was a clear distinction between involvement with faculty and mentoring. Mentoring was operationally defined as an ongoing relationship (e.g., there is someone at the university that you consider a mentor or role model; there is someone who cares about your educational success), whereas involvement with faculty assessed actions such attending office hours or having coffee with a professor. Their results suggest that self-efficacy mediates the relationship between involvement with faculty and academic achievement. There was no significant relationship between mentoring and academic achievement; however, mentoring was positively correlated with self-efficacy. Their findings are consistent with the literature which suggests an inconsistent relationship between mentoring and academic performance (Palmer \& Gasman, 2008; Strayhorn \& Saddler, 2009; Strayhorn \& Terrell, 2007). However, they also present evidence for the significance of the relationship between faculty and Black and Latinx students in relation to self-efficacy and academic performance.

A more recent study examined the impact of variables such as college selfefficacy, perception of mentorship, high school GPA, ACT scores, and first semester college GPA on the intention to persist for first-year college students (Baier, Markman, 
Pernice-Duca, 2016). Their results indicated that college self-efficacy and perceptions of mentorship were the strongest predictors of students' intent to persist.

In addition to collegiate persistence, another study identified a relationship between college self-efficacy and career related outcomes (Hull-Blanks, et al., 2005). Hull-Blanks and colleagues (2005) examined the relationship between self-efficacy, retention, academic performance, self-esteem, career goals, and career commitment. Their results indicated that students with job-related goals were more likely to persist than with unidentified goals. Additionally, their results indicate a significant positive correlation between self-efficacy and school and career commitment. Their findings are consistent with Bandura's (1977) theory which suggests that self-efficacy is related to persistence on a given task. Further their results provide evidence for self-efficacy in relation to career related variables.

Career Self Efficacy. Hackett and Betz (1981) first introduced Bandura’s (1977; 1989) theory of self-efficacy and social cognitive learning to the field of vocational psychology with a conceptual paper that applied the theory to women's career development. In this paper, Hackett and Betz (1981) used the four sources of selfefficacy (i.e., performance accomplishments, vicarious learning, emotional arousal, and verbal persuasion) to articulate the impact of socialization on the career development of women. This brilliant application and integration of distinct theories engendered a large body of literature around career self-efficacy and eventually influenced literature on career decision (Betz \& Hackett, 2006; Betz, Klein, \& Taylor, 1996; Taylor \& Betz, 1983). 
While career decision making self-efficacy has been widely researched and positively related to a plethora of variables, it has been noted that the construct looks different across cultures (Mau, 2000). A study by Gloria and Hird (1999) suggested that there was a significant relationship between career decision making self-efficacy and ethnic identity but only for ethnic minority students as opposed to their White counterparts. Additionally, a study by Bullock-Yowell, Andrews, and Buzzetta (2011) found a negative correlation between career decision-making and cultural mistrust for Black college students suggesting that experiences of racism has a negative influence on thoughts about career. Further, these studies suggest that identity of the individual and their experiences influence the confidence one has in their ability to accomplish career related tasks. Given the current study's focus on Black male college students, findings related to cultural differences in the experience of theory are imperative.

\section{The Current Study}

This dissertation attempts to capture the impact of a Black men's initiative (BMI) at the University of Missouri (MU OR "Mizzou"). MU is a land-grant research institution that was founded in 1839 , in the middle of Missouri. It was also the first public university established west of the Mississippi River. MU is where the world's first journalism school and is one of only five universities in the United States that is home to law school, medical school, veterinary school, and a nuclear research reactor (Curators of the University of Missouri 1997-2002, 2019).

Despite its academic notoriety, Mizzou has a troubling past regarding issues of race and diversity. It should also be noted that Mizzou was founded as an educational institution for White men, women were not admitted into the university until 1867. It was 
not until 1950 that the first Black student, Gus T. Ridgel, was admitted to the university (Curators of the University of Missouri 1997-2002, 2019). In the sixty plus years since Ridgel's admission, MU has still experienced many racially charged incidents. Of note, student led protests in the fall semester of 2015 that resulted in the resignation of University of Missouri Systems President, Tim Wolfe, and MU Chancellor, Richard Bowen Loftin. These protests were the result of Black student activists calling upon administrator after multiple incidents that made Black students feel unsafe on campus (VanDelinder, 2015). Since these protests, the University of Missouri has attempted to address issues of diversity by developing initiatives to hire faculty members of color and creating a department of Inclusion, Diversity, and Equity, which houses the BMI evaluated by the current study.

As previously mentioned, the University of Missouri is a Predominantly White Institution (PWI). In the fall of 2020, MU's total enrollment included 31,103 total students, of which $78 \%$ were White. In total there were 2,061 students who identified as Black, 800 identified as Black men (University of Missouri, 2020). The BMI at MU, named The Mizzou Black Men’s Initiative, was designed to support Black males transitioning into the environment at Mizzou (McElderry, et al., 2018). The program was founded in 2011 with funding from grants and local donors. Currently, the program is housed within the MU Gaines-Oldham Black Culture Center and receives funding from the department of Inclusion, Diversity, and Equity. Despite the growth and longevity of this BMI at MU and others at PWIs across the country, there has been little research to understand the impact of such initiatives. 
A recent study by Brooms (2018) conducted a qualitative analysis of students' participation in BMI programs located at PWIs across the country. Brooms (2018) conducted semi-structured individual interviews with approximately 63 Black male college students from 3 different BMI programs. Each of the programs operated with a different focus. One focused on academic and social cohesion, the next on mentoring, and the last on retention. Brooms's (2018) findings suggest that students' involvement in BMI programs promoted their sense of belonging and mattering on campus. Several themes were identified from the data: accessing sociocultural capital, providing holistic support, focus on Black male identity, and engendering Black male persistence. Brooms (2018) suggests that these themes are areas of strength that foster the sense of belonging and mattering for Black male students. This study is of keen relevance to the current study because it provides evidence for Strayhorn's (2019) elements of belonging and it provides results on the impact of BMIs. While the BMIs identified as part of Brooms's (2018) study have different lenses of focus, each of them are related to the guidelines of the current study's intervention.

As previously mentioned, the BMI that was investigated as a part of the current study follows the programming guidelines described by McElderry and colleagues (2018). This intervention is a two-semester course designed specifically for Black men coming into their first year in college. Using theoretical frameworks of belongingness (Strayhorn, 2019) and racial identity (Cross, 1995), this BMI hopes to facilitate the transition from high school to college. The current study tests the theoretical background of the intervention by capturing the impact of the BMI on constructs like belonging, Black racial identity, and self-efficacy. 
Belongingness has been positively related to a plethora of academic related variables such as retention, involvement in student organizations, academic achievement, motivation, and psychological adjustment (Pittman \& Richmond, 2007; 2008; Guiffrida, Lynch, Wall, \& Abel, 2013; Strayhorn, 2019; Strayhorn \& Mullins, 2012). Generally, research supports the notion that involvement on campus or participation in a campus intervention promotes an increased sense of belonging for college students (Strayhorn, 2019); however, studies suggest that this is not always the case for Black students (Hausmann, et al., 2009). Belonging for Black men has been related to involvement in student organizations and leadership positions on campus (Harper \& Quaye, 2009) and influenced positive academic outcomes such as college adjustment, college satisfaction, and academic performance (Strayhorn, 2019; Strayhorn \& Mullins, 2012). While belonging has been explored as a construct relevant to the experience of Black college students and even Black men specifically, it has not been explored in relation to Black racial identity development.

Black racial identity has been positively associated with self-esteem, psychological well-being, and self-efficacy (Gushue, 2006; Pillay, 2005; Rowley, et al., 1998). Academically, racial identity development has been associated with academic performance and intention to persist to graduation (Chavous, et al., 2003). While research has not connected Black racial identity to belongingness, there is a strong connection to self-efficacy (Gushue, 2006; Reid, 2013; Smith, Walker, Fields, Brookins, \& Seay, 1999; Witherspoon, Speight, \& Thomas, 1997).

While not addressed directly in the theoretical framework of McElderry and colleagues (2018), the current study will assess the impact of BMI on self-efficacy 
because of its significance in higher education literature (Solberg, et al., 1993). The literature suggests that self-efficacy is positively related to intention to persist, college adjustment, academic performance, life satisfaction and college satisfaction (Baier, Markman, \& Pernice-Duca, 2016; Betz \& Hackett, 1981; Coffman \& Gilligan, 2002; DeWitz \& Walsh, 2002; Ramos-Sanchez \& Nichols, 2011; Vuong, Brown-Welty, \& Tracz, 2010). Additionally, self-efficacy literature suggests that both theoretical frameworks of belonging and Black racial identity are significant predictors of selfefficacy (Freeman, Anderman, \& Jensen, 2007; Gushue, 2006; Reid, 2013; Uwah, McMahon, \& Furlow, 2008). Given the theoretical background of the intervention and literature that suggest a link to self-efficacy, the current evaluation will attempt to capture the impact of the BMI on belonging, Black racial identity development, college selfefficacy, and career decision making self-efficacy.

\section{Research Questions}

The current study employs an explanatory mixed methods approach to evaluate the impact of a BMI program on the first-year experience of college students. The study aims to capture this impact by asking the following questions of the data:

1. What is the impact of this intervention on participants' academic related variables (i.e., retention and performance)?

2. How does this intervention influence racial identity development, sense of belonging, college self-efficacy, and career decision-making self-efficacy?

3. What is the experience of participants in the intervention? 


\section{CHAPTER III}

\section{Method}

Given the nature of this intervention, designed for a small group of Black men enrolled at a PWI, it was imperative to pair the objectivity of quantitative analysis with the depth in the narratives provided from qualitative inquiry. As further discussed below, this pairing allows for analysis that is not solely based on statistical power. Thus, the current study employed an explanatory mixed methods approach (Creswell \& Clark, 2017; Ivankova, Creswell, \& Stick, 2006).

The nature of an explanatory approach is to work in two phases beginning with the quantitative phase, followed by the qualitative phase. The quantitative analysis facilitates a statistical evaluation of the intervention and the qualitative inquiry provides an in-depth explanation of the quantitative results. Similar approaches have been used with student populations in higher education (Ivankova \& Stick, 2007).

Brenner and colleagues (2014) used an explanatory mixed methods approach to evaluate an intervention for healthcare providers. While their study produced significant findings, Brenner and colleagues' (2014) study is salient to the current project because of the rationale discussed for pairing a quasi-experimental design with qualitative analysis to produce robust results. They argue that a mixed methods approach provides a comprehensive understanding of complex constructs, allows researchers to keep a broad scope to investigate the effect of the intervention (whether intended/unintended or measured/unmeasured), and to increase credibility and validity of the results. In addition to the arguments laid out by Brenner and colleagues (2014), a mixed methods approach is appropriate for the current project because it lends voice to marginalized identities and 
attempts to validate the interventions designed to serve them. Reliance solely on quantitative analysis shifts power and political favor in the direction of intervention designed for larger populations and further disenfranchises those designed for groups with small numerical influence.

Similar to Brenner and colleagues (2014), the current study utilized a quasiexperimental research design for the quantitative phase of the project. While not as robust as a randomized controlled trial (RCT), quasi-experimental designs have been used to assess interventions across a plethora of disciplines (Brenner, et al., 2014; Gustafsson \& Borglin, 2013; Krishnan \& Sitaraman, 2013; Peterson, 2016; Roe, Hasson-Ohayon, Mashiach-Eizenberg, Derhy, Lysaker, \& Yanos, 2014). The inclusion of a control/comparison group is generally accepted when randomization is not a viable option.

The qualitative phase of the project employed a case study design. Yin (1992) argues that case study is ideal when conducting program evaluation. In his writing, Yin (1992) asserts that case study is appropriate because it includes multiple sources of data and investigates a phenomenon within its natural context as opposed to pure quantitative analysis that does not capture the same depth as qualitative data. Further, Yin (1992) suggests that other qualitative traditions such as grounded theory and ethnography are better suited for tasks such as theory development rather than theory testing. In addition, he suggests that ethnographic studies assume multiple realities and therefore are not ideal to provide objective inquiry of program design and grounded theory traditionally is restricted to the use of only qualitative data as opposed to the inclusion of multiple data sources. Given the explanatory mixed methods approach discussed, along with the 
appropriate boundary of the intervention as a case, phase two of the current project employed a case study design for the qualitative inquiry of the data.

\section{Participants}

The current study solicited a total of 47 first-year, 18-19 year old, Black male students from a large PWI located in the Midwestern region of the United States. Approximately $60 \%$ of participants were enrolled in the intervention group $(n=28)$ while the comparison group consisted of the remaining $40 \%(n=19)$.

The intervention group and comparison group were similar across general demographic information such as race, age, gender, classification, and first-generation status. Differences between the groups were observed in high school GPA and means by which they plan to finance their education. Of note, approximately $14.3 \%$ of the intervention group graduated with High School GPAs below a 3.0 compared to $26.4 \%$ of the comparison group. Additionally, $96.4 \%$ of the intervention group is receiving some form of scholarship as opposed to $68.4 \%$ of the comparison group.

\section{Measures}

Demographic Questionnaire. A questionnaire was constructed to assess participants' demographic information. It consisted of questions used to assess students' age, ethnicity, nationality, first generation status, socio-economic status, financial resources (i.e., how they intend to pay tuition and living expenses), self-reported high school GPA, community type (e.g., rural, urban, suburban), collegiate major, and intended occupation.

Belongingness. Previous studies of school belonging on college campuses have employed modified versions of the Psychological Sense of School Membership (PSSM; 
Goodenow, 1993) to measure school belonging (Pittman \& Richmond, 2007; 2008).

However, as established by Slaten and colleagues (2014), school belonging looks different at the collegiate level. Thus, the University Belonging Questionnaire (UBQ; Slaten, Elison, Deemer, Hughes, \& Shemwell, 2017) was developed and validated as a measure of belongingness at the university level.

The UBQ (Slaten et al., 2017) was used to assess students' level of belongingness. The UBQ is a 24-item questionnaire designed to measure belongingness as specific to college students' experience of the construct. Students will rate each item on a 4-point Likert scale ranging from 1 (strongly disagree) to 4 (strongly agree). Items were developed based on the findings of a qualitative study designed to understand factors that influence college students' experience of belonging (Slaten et al., 2014) and the questionnaire was developed and validated through the use of both an exploratory factor analysis (EFA) and confirmatory factor analysis (CFA) (Slaten et al., 2017). The UBQ consists of three subscales: university affiliation, university support and acceptance, and faculty and staff relations. Overall, the measure had a strong internal consistency reliability of .94 , in addition to good construct, discriminant, and incremental validity (Slaten et al., 2017).

University affiliation subscale is a measure of perceived membership to the university and/or pride in one's membership. This subscale includes items such as "I take pride in wearing my university's colors," "I feel at home on my campus," or "I am proud to be a student at my university." The university affiliation subscale is the largest of the three (12-items) and had high internal reliability (Cronbach's alpha $=.92)$. 
The university support and acceptance subscale is an 8-item scale designed to assess the extent to which students feel supported and accepted by the university. This scale includes items such as "I believe there are supportive resources available to me on campus," or "my cultural customs are accepted at my university." The university support and acceptance subscale was also found to have good internal reliability (Cronbach's alpha $=.85)$.

The third subscale of faculty and staff relations is a 4-item scale designed to assess the significance of students' relationship with university affiliated personnel. The scale includes items related to students' feelings of connection to one or more faculty/staff member such as "I feel connected to a faculty/staff member at my university," or "I believe that a faculty/staff member at my university cares about me." The internal reliability for the faculty and staff relations scale was also relatively high (Cronbach's alpha=.88).

Racial Identity. The Cross Racial Identity Scale (CRIS; Cross \& Vandiver, 2001) was used to assess participants' racial identity development. The CRIS consists of 40items, measured on a 7-point Likert scale (ranging from 1=strongly disagree to $7=$ strongly agree). Each item is designed to measure participants' thoughts as they relate to Cross's (1995) Nigrescence model of Black racial identity development across six subscales: (1) Pre-Encounter Assimilation, (2) Pre-Encounter Miseducation, (3) PreEncounter Self-Hatred, (4) Immersion-Emersion Anti-White, (5) Internalization Afrocentricity, and (6) Internalization Multiculturalist Inclusive.

The CRIS has been tested and validated through a number of studies (Cokley, 2002; Cross \& Vandiver, 2001; Vandiver et al., 2000). Studies have found good levels of 
internal consistency among the subscales of the questionnaire. The Pre-Encounter Assimilation scale ranged from .74 to .85 , Pre-Encounter Miseducation from .78 to .81 , Pre-Encounter Self-Hatred from .80 to .89 , Immersion-Emersion Anti-White from .81 to .89 , Internalization Afrocentricity has been a consistent .83, and Internalization Multicultural Inclusive ranged from .82 to .83 .

College Self-Efficacy. The College Self-Efficacy Inventory (CSEI; Solberg, O’Brien, Villareal, Kennel, \& Davis, 1993) was used to assess participants'self-efficacy to complete tasks/behaviors to foster success in college. The instrument consists of 20 items and 3 subscales: Course performance, interactions with roommates, and social adjustment. Participants will rate their confidence level for each item on a 10-point Likert scale ranging "0" (not at all confident) to 9 (extremely confident).

The subscales measure the confidence college students feel in their ability to perform in coursework, interact with roommates, and interact socially. Each subscale has been tested and yielded appropriate levels of internal reliability (course $=.88$, roommate $=.83-.88$, social $=.86-.88)$ with overall levels ranging between $.92-.93$ (Gore, Leuwerke, \& Turley, 2006; Solberg et al., 1993).

Career Decision Making Self-Efficacy. The Career Decision Making SelfEfficacy Scale-Short Form (CDMSE-SF; Betz, Klein, \& Taylor, 1996) was used to assess participants' feelings about career related issues. The CDMSE-SF is a 25-item measure designed to assess the extent to which an individual believes they can accomplish tasks related to career decision making. Participants are asked to rate each item on a 10-point Likert scale ranging from 1 (no confidence at all) to 10 (complete confidence). The scale consists of 5 subscales: Self-Appraisal, Occupational Information, Goal Selection, 
Planning, and Problem Solving. The internal consistency of the total CDMSE-SF is a .94 with the consistency for the subscales ranging from .73 to .83 (Betz et al., 1996).

\section{Procedures}

As previously mentioned, the current project employed an explanatory mixed methods approach and therefore consists of two phases: quasi-experimental quantitative design and qualitative case study analysis. Prior to initiating either phase, the project was submitted to the University of Missouri Institutional Review Board (IRB) and approved.

Phase I. Upon IRB approval of the project, participants were solicited in two ways: (1) via email to the incoming first-year class of Black males (2) through the intervention's existing online classroom functions (i.e., email and Canvas website), and (3) the researcher was granted a brief period of classroom time to solicit students from the intervention's existing meeting time.

The program has traditionally solicited applications through email and recruiting at summer orientation events. Applications assess the students' interest in the program, perspectives on leadership, mentoring, and service, as well as anticipated challenges for their experience in college (McElderry, et al., 2018). The leadership team of the program performed a blind review of all applications and accepted students based on the level of support students needed. For the purpose of the program, need is determined by perceived support and anticipated challenges. Students of high need are typically those that are selected for the incoming cohort of the program. The incoming cohort served as the experimental group for the current project.

In order to obtain a comparison group, emails were sent to first-year Black male students prior to the start of the fall semester in order to establish a baseline and identify 
how students perceive themselves before the start of the collegiate career. Data were collected throughout the academic school year with participants receiving $\$ 5$ compensation for each time they completed the survey.

Data Collection Schedule. Phase 1 of the project included three points of data collection where both the experimental group and comparison group were surveyed. First, a baseline was established at the beginning of the fall semester. Baseline data collection for both the experimental and comparison group started on August 25th, 2019 and continued until September 8, 2019. Several emails were sent to all incoming, firstyear, Black male students. The survey was also posted to the Canvas website for the BMI course for students to access if they elected to participate in the experimental group. Baseline surveys returned a total of $N=47$ students; with $n=28$ in the experimental group and $n=19$ in the comparison group.

The survey was distributed again on December 17, 2019, at the beginning of winter break. Participants from both groups received a mass email initially and individualized emails prompting them to complete the midpoint survey. The survey remained open until February 18, 2020, giving participants two months to complete the survey. The midpoint saw a decrease in retention as approximately $42.5 \%$ of participants dropped out of the study from baseline to the second time point. The dropout rate of the experimental group was similar to that of the overall sample (42.9\%), whereas the comparison group experienced a $31.2 \%$ drop out rate. Upon completion of the second time point of data collection, data were analyzed to produce preliminary findings and develop the interview protocol for phase II of the study. 
For the final data collection point surveys were distributed on April 20, 2020 and remained open until May 22, 2020. From time point 2 to the final data collection point the sample experienced an attrition rate of approximately $44.4 \%$ (experimental $=31.2 \%$; comparison $=63.6 \%$ ). It should be noted that the final time point of data collection occurred in the midst of the international crisis that was COVID-19. The university transitioned classes to all remote learning on March 16 and closed facilities on March $23^{\text {rd }}$. Once the final round data collection once complete, phase II of the study began with qualitative interviews.

Quantitative Data Analysis. Given that the conditions of current study are not randomized, descriptive statistics were conducted to test scores and rule-out group differences at baseline. In order to examine change based on the program, an analysis similar to that conducted by Roe and colleagues (2014) was run. Using SPSS 17, a twoway ANOVA was conducted to test for group differences at baseline. In order to assess the impact of the intervention, a repeated measures multivariate analysis of variance (MANOVA) was employed to assess change in variable composite scores over time and across groups. With the current design, participant attrition in the control group is expected. As a result, participants who did not complete all three time points were excluded from the analysis.

Phase II. Following the quantitative analysis, the second phase of the project began. This phase was a qualitative inquiry to glean additional insights from the quantitative results. Specifically, the second phase of the current project was designed from a critical constructivist perspective and used case study as the tradition of inquiry. 
There are several schools of thought regarding case study in qualitative research (Yazan, 2015). The current study aligns closest with Stake's (1978) perspective, which views case study as the inquiry into an integrated system with a boundary and working parts. For the current study, the intervention serves as a bounded system and Phase II investigated the experience of participants within the system of the intervention. Further, Stake (1995) argues for flexibility in the research design by suggesting that research questions should develop alongside researchers' interaction with the case. For the current study, the research questions and specific interview questions were not and could not be developed until the initial interaction with the case (i.e., Phase I) had been completed.

Paradigm. Phase II of the current project employed a critical constructivist perspective (Kincheloe, 2005). This paradigm operates similar to traditional ideas of constructivism, which suggest that knowledge is socially constructed by institutions and members of a given society. However, as the name suggests, critical constructivists apply a critical lens to those traditional ideas and assert that knowledge is inherently political and has power dynamics that empower certain groups and identities while disempowering others.

Procedure. Once the quantitative data collected during Phase I of the study was analyzed and conclusions were drawn, specific interview questions were developed in order to better understand the quantitative results. After finalizing the interview protocol, participants were contacted and scheduled for individual interviews. Interviews were semi-structured in design and lasted approximately 60-75 minutes with $n=9$ participants from both the treatment $(n=6)$ and control $(n=3)$ groups. Additionally, each interview was audio recorded stored in a secure digital file. In order to maintain confidentiality of the 
participants, they were asked to provide a pseudonym to protect their identity (see Table 5).

After the completion of interviews, the audio files were transcribed by a private transcription service. When transcripts were received, they were read and edited for errors in language, grammar, and/or context.

Analysis. Consistent with Stake's (1995) recommendations for data analysis, the current study used categorical aggregation and direct interpretation to give meaning to the data. Categorical aggregation is the process of developing themes and/or clusters by which to organize data. Direct interpretation is the process of developing new meaning from the data.

Trustworthiness. In order to counter ideas that question the rigor of qualitative inquiry, Lincoln and Guba (1985) identified several ways to establish trustworthiness: credibility, transferability, dependability, and confirmability.

Regarding credibility, the analysis accounts for trust of participants by conducting member checks throughout the interview process and manages risk for researcher bias, by triangulating qualitative data with quantitative analysis. In addition, researcher bias was managed by setting aside theoretical influences while developing the interview protocol and during the initial coding stage. Concerns of salient themes, misinformation, and atypical responses were managed through peer debriefing (Padgett, Mathew, \& Conte, 2004) and constant comparison (Glasser, 1965).

In order to promote transferability, thick descriptions of all procedures are provided so that researchers can replicate the study to the best of their ability. In their description, Lincoln and Guba (1985) suggested that it is the job of the researcher to 
provide information for the reader to make judgments about the transferability of the paper. They also suggested thick description as the best method of providing readers with the proper context of the findings generated from a given study.

Threats to dependability are accuracy, the Hawthorne effect, and inquirer sophistication. In order to account for the accuracy of the findings, data were audited, and the researcher will debrief with peers and experts throughout the analysis process. The Hawthorne effect, when participants may alter their behavior or responses because their awareness of researcher evaluation (Cook, 1962), was managed through the triangulation of data. Inquirer sophistication was navigated by employing separate techniques: analysis of researcher's role and expert debrief. Throughout the current study, the researcher was mindful and transparent about his role as a Black male student and as the interviewer. Further, the researcher engaged in monthly meetings with a methodology expert.

The last category of trustworthiness as described by Lincoln and Guba (1985) is confirmability. Peer and expert debriefing were utilized throughout the process of the research in order to ensure that findings are grounded in data, inferences are logical, and rationale for categories is solid. In order to accommodate negative evidence, the constant comparison method (Glasser, 1965), member checking, and negative case analysis were used (Lincoln \& Guba, 1985). 


\section{CHAPTER IV}

\section{Results}

While limitations are discussed in depth in Chapter V (Discussion), it is impossible to separate certain limitations from the results of the current study as they are a significant part of the experience for participants. The academic year examined by the current study was an anomaly for many reasons. The most significant being the impact of the global pandemic of COVID-19 that was, at minimum, a significant disruption in the typical first-year college experience. The onset of COVID-19 forced the campus to shut down which made most students return home, and all students to transition to online coursework. The university transitioned to remote learning on March 16, 2020 and closed facilities during spring break on March $23^{\text {rd }}, 2020$. Additionally, recent studies have indicated a decrease in student engagement and motivation as a result of the COVID-19 pandemic (Al-Kumaim, et al., 2021; Daniels, Goegan, \& Parker, 2021). From a broader perspective, the global pandemic resulted in the loss of loved ones, changes in employment status or financial security, increased stress, and higher rates of mental health issues (Pfefferbaum \& North, 2020; Prime, Wade, \& Brown, 2020).

It is also imperative to capture the context of the University of Missouri during the 2019-2020 academic year. Not only did the university face the pandemic of COVID19 but there were also several incidents with race at the center of the controversary. In April of 2019 it was announced that the Vice Chancellor of Inclusion, Diversity, and Equity (IDE) was leaving Mizzou for another institution (Cartwright, 2019). The new Vice Chancellor, Maurice Gipson, was introduced on July 14, 2020 (Gipson, 2020). As 
such, IDE (and subsequently the BMI) was under the direction of interim Vice Chancellor, NaTashua Davis for the academic year of 2019-2020.

Regarding the BMI examined by the current study, this specific year was different than others prior to the onset of COVID-19 pandemic. After discussion with the BMI director, who serves as the instructor for the course and facilitator of all events, he revealed that during the fall semester he was absent for approximately one month while attempting to recover from a significant illness. As a result, his teacher's assistant (TA) led many of the course discussions and many events scheduled for the fall semester were rescheduled to happen in the spring. While the TA was trained by the director and spent a total of two years in the program, one as a cohort member and another as a peer mentor, he was an undergraduate student that does not have the same level of expertise as the program director. Included in their rescheduled events was the "Lock In" experience that typically takes place during the fall semester and is used to break down barriers and establish connections among the BMI cohort.

Lastly, qualitative interviews were conducted in the months between May and July of 2020. As such, some of the interviews were conducted prior to the killings of Ahmuad Arbery, Breonna Taylor, and George Floyd and others were conducted afterward. Considering the shared identity of the researcher and the participants as Black men, these killings and the widely publicized protests surrounding them were discussed in half of the qualitative interviews. The impact of these events cannot be understated, as these killings sparked responses from non-Black individuals, many corporations, and institutions, including the University of Missouri. On May 28, 2020, UM Systems released a statement condemning discrimination and violence (Bacharier, 2020). It should 
be noted that shortly after the killing of George Floyd two incoming students posted a snapchat video mocking the death of George Floyd (Bacharier, 2020). The UM systems President released a statement announcing that the student would be suspended (Choi, 2020). This resulted in backlash from students and faculty who desired a stronger response from the university. Many took to social media using the hashtag \#BlackatMizzou where current students and alumni detailed experiences of racial discrimination and systemic issues within the university (McKinney, 2020). This is important context to the current study, given the identities of the participants as their experience on campus was likely impacted by the killings, the protests, as well as the university and societal response to these events.

Given the many emotional, academic, and experiential factors associated with these experiences, their impact cannot be ignored when considering the results of the current study. Specifically, considering participants' motivation and desire to remain engaged in research participation.

A total of 13 participants completed the quantitative survey at all three data collection points throughout the academic year; however, at baseline there were a total of 47 participants to complete the survey, resulting in an overall attrition rate of $72.3 \%$. A power analysis revealed that an $\mathrm{n}$ of approximately 34 was needed to obtain statistical power. As such, the overall sample size $(n=13)$ of participants to complete each phase of data collection did not meet the statistical power needed to draw general conclusions about the influence of the BMI intervention on the variables examined by the current study. Rather, data from Phase I were examined for changes in the means over time and employed as a means for triangulation with qualitative data from Phase II of the study. 


\section{Phase I Results: Quantitative Analysis}

Research Question 1: What is the impact of this intervention on participants' academic related variables (i.e., retention and performance)?

Academic Achievement. A one-way analysis of variance (ANOVA) was run to determine differences in academic achievement (i.e., GPA) between the treatment group (BMI) and control group at the end of the academic year. The analysis revealed no statistical difference between the treatment and control group $F(1,8)=.054, \mathrm{p}=.821$. Participants in the treatment group $(n=8 ; M=3.37)$ finished the academic year with similar GPAs to participants in the control group $(n=2 ; M=3.30)$. As previously mentioned, these quantitative findings are inconclusive given the small sample size.

Given the high level of attrition, academic achievement data were also collected from the BMI program director. In the fall semester of 2019 students in the BMI completed their first semester with an average GPA of 2.89 which is comparable to the average male first year students' GPA of 2.87 in that semester. In the spring semester of 2020, the semester significantly impacted by COVID-19 safety protocols, students in the BMI averaged a 3.55 GPA. In contrast, the average for first-year male students at the university for that spring semester was 3.25. The cumulative GPA for students in the BMI was 3.11, whereas first-year male students averaged a 3.05 GPA (Office of the University Registrar, 2021).

Retention. Similar to academic achievement, data were collected from the BMI director regarding the first-year to second-year retention of students enrolled in the BMI. Based on the data collected, 24 of 27 students in the BMI, or $88 \%$, were retained from year one to year two. This rate is comparable to $87 \%$ of first-year males at the university 
at large retained from the academic year of 2019-2020 to 2020-2021 (U.S. News \& World Report, 2021).

Additionally, a repeated measures ANOVA was run to determine the impact of BMI intervention on participants' intent to persist. The results indicate that there was no statistically significant difference between the treatment and control group $F(1,12)=2.545 ; \mathrm{p}=.137$.

\section{Research Question 2. How does this intervention influence racial identity} development, university belongingness, university mattering, college self-efficacy, and career decision-making self-efficacy?

Repeated measures ANOVAs were run to determine the effects of the BMI on outcome variables such as racial identity development, university belongingness, university mattering, college self-efficacy, and career decision-making self-efficacy. A statistical significant difference was observed on the CRIS subscale of ImmersionEmersion Anti White, $\mathrm{F}(1,11)=6.023, \mathrm{p}=.032$. However, no statistically significant difference was observed between the treatment and control group on the remaining variables mentioned, including the remaining CRIS subscales. As previously mentioned, these results should be interpreted with caution given the high level of attrition experienced throughout the course of the study. These results indicate that participants who were in the BMI experienced significantly more change over time than the control group . Trends in the means suggest that participants in the BMI simply experienced greater variability in their Anti-White sentiments over time than their counterparts in the control group. 
Given the small sample of participants who completed data collection through all three data points, a robust analysis such as repeated measures ANOVA, may not be the most appropriate way to demonstrate statistical differences. As such, effect sizes were calculated for both within group and between group differences among all outcome variables (Cohen, 1988).

Within-Group Differences. Results for within group differences are displayed in Table 1. Analysis indicates a medium effect size from baseline to post-test for the treatment group on interpersonal variables such as University Belonging (UBQ; $d=.57$ ), College Self-Efficacy (CSEI; $d=.51$ ), and Career-Decision Making Self Efficacy (CDMSE; $d=.58$ ); however, there was a small effect size for University Mattering (UMS; $d=.36$ ). In contrast, results for the control group indicate a small effect size for the amount of change between baseline and post-test for interpersonal variables: UBQ $(\mathrm{d}=.05), \operatorname{CSEI}(d=.06), \operatorname{CDMSE}(d=.41)$, and UMS $(d=.33)$. These results suggest that participants in the BMI made moderate increases on UBQ, CSEI, and CDMSE.

Regarding racial identity, within group differences are displayed in Table 2. Analysis revealed large effect sizes for the treatment group on Pre-encounter miseducation $(d=1.52)$ and Pre-Encounter Self-Hatred $(d=.89)$, a medium effect size on Afrocentricity $(d=.53)$ and small effect sizes for Pre-Encounter Assimilation $(d=26)$, Multicultural Inclusive ( $d=.42)$, and Immersion-Emersion Anti-White ( $d=.17)$. A large effect size was also revealed for the control group on Pre-Encounter Miseducation $(d=1.17)$. The control group also observed a medium effect size on Pre-Encounter Assimilation ( $d=.66)$ and Afrocentricity $(d=.54)$, while a small effect size was observed on Immersion-Emersion Anti-White ( $d=.32)$, Pre-Encounter Self Hatred $(d=.25)$, and 
Multicultural Inclusive $(d=0)$. These results suggest that participants of both the treatment and control groups experienced a large change on the Miseducation scale and moderate amount of change on the Afrocentricity scale. Additionally,

Between-Group Differences. Results for between-group differences were based solely on the post-test scores on each variable. Between-group differences for interpersonal variables are represented in Table 3. Results indicate a large effect size for CSEI $(d=.93)$ and UMS $(d=1.54)$. This indicates that a large difference was observed between the treatment $(M=123.12)$ and control group $(M=102.75)$ on CSEI. The same was observed for UMS but the treatment group (M=68.12) had lower scores than the control group (M=75). The effect size for UBQ $(d=.13)$ and CDMSE $(d=.16)$ were both small, indicating negligible difference between the groups.

Between-group differences for racial identity development measures are displayed in Table 4. Results indicate a large effect size for Pre-Education Self-Hatred $(d=1.36)$ and Multicultural Inclusive $(d=1.18)$. Specifically, scores on the Self-hatred reveal that the treatment group $(M=7.11)$ endorsed these items at a lower average than their counterparts in the control group $(M=11.75)$. Conversely, on Multicultural Inclusive ratings participants in the control group (M=33.5) endorsed these items at a higher rate than the treatment group $(M=30.22)$. A medium effect size was observed on the Afrocentricity scale $(d=.50)$. This suggest that the difference between the treatment $(M=14.77)$ and the control $(M=12.25)$ groups is moderate. All other scales of racial identity development revealed low effect sizes: Assimilation $(d=.06)$, Anti-White $(d=.18)$, and Miseducation $(d=.45)$.

\section{Phase II Results: Qualitative Analysis}




\section{Research Question 3: What is the experience of participants in the}

\section{intervention?}

In order to answer the third research question of the current study, a qualitative case study analysis including categorical aggregation and direct interpretation was conducted Stake (1978; 1995). Just as suggested by Stake (1995), flexibility in the research was demonstrated by allowing for themes to organically present themselves and by the research questions developing as the researcher interacted with the case. As such, it is important to establish context for the data before discussing the themes. For the current study and analysis, the context is a point of agreement between all participants, both treatment and control. Through all the interviews, it was established that all participants experienced the campus as racialized. In other words, all participants noted a stark difference between the cultural experience of Black students on the campus when compared to their White counterparts. While few participants shared personal experiences of discrimination, they all discussed their awareness of racial differences and the history of racism at the university.

After coding and analyzing the data, the following themes emerged as salient to participants who participated in the BMI: (1) COVID-19, (2) Access and (3) Identity Development. In Table 6, the subordinate themes that contribute to each superordinate theme are displayed.

\section{COVID-19}

The academic year in which data were collected was an anomaly as it captures the onset of the COVID-19 pandemic. This experience had a dramatic impact on the world and college students were not exempt from this. Participants identified many ways 
COVID-19 impacted their first year of college: (1) academic adjustment, (2) missed opportunities, and (3) safety concerns.

Academic Adjustment. As the COVID-19 pandemic began and communities all over began to implement "shelter in place" orders, many universities closed their campuses and transitioned courses to online formats. Participants discussed this experience as disorienting, and many described the transition to remote learning as difficult to navigate. They shared stories of struggling to keep up with the schedule and the workload, leaving them to fall behind in multiple classes. Ultimately, they reported adjusting their academic approach and finding a way to salvage their grades before the spring semester's end. Nathaniel discussed his falling behind on work and taking three weeks to adjust, "since class was just my laptop for a while and I actually like being in class because I learn better that way. I neglected my classes for three weeks. That was bad and definitely did not help anything. And then, I just had a turnaround point and I caught up on three weeks of work. And when [inaudible] got back to where I was and I was like, I need to finish this." Matthew also reported starting his remote learning experience without structure and falling behind:

So, at first, I was just in bed, kind of just taking it as a extended break. But after a while, I just had to really put some structure into my days, into my weeks because the biggest thing that it took away probably was the structure that I had in place. So I had to reimplement that back into my life, so I could really have things that I'm working towards, have tasks that I'm doing. So I also had to really stay because I like to work out and stuff like that, so I had to really be [on it?] about that as well. Yeah. 
Missed Opportunities. While participants discussed the adjustments they had to make after COVID-19 ended their on-campus experience, they also discussed opportunities that they missed out on all together. Many pointed out missing a large part of their social experience while others also discussed opportunities for either academic, professional, or personal advancement. Jet described this experience for himself as he captured the challenge from an athlete perspective.

I think not just me, but every student this year just-- we got cut short, so a lot of us had to stay home. I mean, that's a one big impact that we all had to experience. I'd say, for me, personally, it really-- I feel just stunted a lot of development I had. I don't think I told you. I joined the football team this spring, and it being my first year, and so this whole spring was supposed to be that time where you're supposed to get stronger, bigger with that lifting plan they have for you, and gain weight and all that. And we didn't really get too many practices in before we had to go home. So being here, I just feel like all that I could have done, all my development was kind of stunted because no matter what you're doing here to work out and stay in shape, it's not the same. So that was tough. That was tough. When considering participants of the BMI specifically, many participants mentioned the BMI service trip being cancelled as a result of COVID-19. Ray expressed this sentiment during his interview: "I didn't think it would have as much of a negative impact as it did. But of course it did. It just continuously got worse. It kind of canceled-we were supposed to go [inaudible] my service trip. That got canceled, of course. That was something I was really looking forward to.” 
Safety Concerns. Participants also expressed feelings of anxiety surrounding their personal health as well as that of their families. Udo shared that his mother was a nurse, and he revealed his experience of rationalizing his concerns for her safety:

My mom's a nurse, so there's times when she has to work with people who have COVID. That's a little concerning. Hopefully, she doesn't come back and bring it here.....I mean, I was just sitting here [hoping] she come back healthy and not sick. That's good. And she doesn't work a whole lot. I would say three days a week at most, so better than five days a week, which she would usually work. Of note, participants also expressed concerns about their families' financial wellbeing. MoFeezy talks about his parents' financial woes and mentions the possibility of contributing to help his family stay afloat.

Yeah. So my dad hasn't been working for a while now, but I think he goes back by 18th, I think. I don't know for certain. My mom, while she's still working right now, she just got notified that she will be getting laid off. So she thinks that's coming up sometime around June. It's when that's going to happen. Luckily, I have a job opportunity for over the summer that will be paying a decent amount, and if it comes down to and I need to help provide them, I will be making enough to do so.

\section{Access}

As participants reflected on the experience of their first year of college, they consistently discussed the level of access they were permitted to different aspects of the college experience. Specifically, several sub-domains emerged as points of access for participants in the BMI: Support, Involvement, and Socio-Cultural Capital. 
Support. In discussing their experience, participants in the BMI shared many points of support they received that was specific to the BMI intervention. While participants from both groups shared experiences of interactions participants in the BMI intervention discussed specific experiences with mentors and staff that provided leadership and guidance. Many discussed this part of the BMI as a valued part of their experience and one that made them feel like they mattered on campus. MoFeezy recalled a specific experience with the director of the program that made him feel like he mattered as an individual.

I even had a little personal dispute in the middle of the year, and [BMI Director] acted as a mediator. And sat between me and him. And we all sat down and had a conversation. Didn't really outcome in anything, but he tried. You know what I mean? .....I noticed that. That's not something that he necessarily had to do. That's probably not in his job description that says, if two students are arguing, you have to mediate. So no, he went out of his way to do that. And that was one of the instances where I said, this guy truly cares about this program. He cares about the people here. I matter to this person.

Additionally, participants of the intervention group all mentioned the structure and workload required by the BMI. Some were critical of the program, citing the amount of work they were expected to complete. Eli Shane illustrated this point by stating "I think the only problem I had with [the BMI] is just kind of the workload, but that was all especially for being one-credit hour with that much work." In contrast, participants also mentioned the required study halls as a supportive part of their experience and one that helped them academically. Nathaniel discussed his experience in study hall as a place 
where he could receive insight from the leadership team of the BMI. He stated, "anytime I went to study hall, aside from just the guys in [BMI], I also had the peer mentors there. And they're sophomores. They had already been through some of the stuff I've been through in their majors or similar. They could hook me up with somebody that was."

Involvement. In qualitative interviews, participants in the BMI mentioned greater levels of campus involvement than the control group. This claim was corroborated through triangulation of the data with the quantitative analysis. Additionally, participants in the BMI seemed to get involved in campus organizations sooner than their counterparts in the control group. Specifically, participants in the BMI were able to get involved in campus organizations serving Black students or students of color. Brian, who was a participant from the control group reported feeling overwhelmed by the amount of organizations and missing information on how to join certain organizations, as a result, he delayed his involvement.

I think I was just like a little overwhelmed by the amount of clubs there were, and I wanted to really be involved. I didn't really know what I wanted to do yet. So that's why I gave myself a semester off to decide and then just kind of didn't [inaudible] know if I wanted to do.... There's like NABA, and then there is DSA, which is diverse students association that I really wanted to join. There is a business frat that I wanted to join, but I don't think I-- I think I missed the [signed out?] paper or something. There is a list of things that I want to join this upcoming semester. 
Generally, participants in the BMI did not discuss campus involvement with the same confusion and anxiety as those in the control group. In fact, Jet's casual discussion of his involvement on campus illustrates a stark contrast to the experience of Brian.

So I say ASA, MIS, [BMI], KCOU, KOMU. I feel like there's one or two more, but that's all that's coming to mind right now. But based on that, I feel like I'm the right kind of involved. I'm not too involved because I'm not that person who wants to just get involved in everything just to say, "I'm in this." But I feel like I'm involved in the way I should be. I'm managing what I can manage and joining what interests me, what I value.

Participants in the BMI intervention also discussed community involvement through various community service projects. Some participants mentioned these events creating a point of connection between them and the community.

with [BMI], we volunteered at several places in the community. I think it's the blind center, blind boot center. It's something like that. It's kind of like a, I guess, after-school for kids or something like that, little school for kids. So we volunteered there. We volunteered at another kids' center. I forget that name, but that's in Columbia as well. And that was all through [BMI] our service project, so. Those were one of the times where I felt like I was part of the community, amongst the community, helping out the community.

Socio-Cultural Capital. One of the most salient aspects of participants' experience of the BMI was the unique access to Socio-Cultural Capital on campus. All participants of the treatment group discussed the benefit of coming into the program and immediately having a group of peers with shared identities; however, the extent of their 
access to community became more apparent in the interviews with participants of the control group. Participants in the control group shared a vastly different experience with community and specifically gaining access to the Black community on campus than did the participants in the treatment group. Brian, a participant in the control group, recalled an article he read around homecoming that captured his experience on campus.

there was an article written about black. You should be a part of [the University] that like somebody has wrote, and one of the quotes was not-- from one of the students, one of the quotes was "not everybody is a part of black [University], but the people who are, are unified," and that kind of threw me off because, like I didn't know what you have to do. You should be a part of black [University]. I kind of thought, it was a given thing if you're black, and then it's kind of the attitude. A lot of the black people here have, I feel-- I feel like if you're not black enough, then they don't consider you a part of the community, and that's with my experience I get from black community.

As Brian recalled this article and related it to his own experience, he acknowledged the distinct culture of the Black community on his campus and the exclusivity of it that requires access. Conversely, participants in the treatment group referred to the Black community at the university and the spaces held by the Black community with much more affection than their counterparts in the treatment group. They seemed to find a sense of solace within the community.

$[\mathrm{BMI}]$ and the [Black Culture Center] felt like home away from home. I needed somewhere to crash, maybe my dorm, maybe the student center, but the Black Culture Center was just a nice place. So it went from being somewhere where I 
was uncomfortable and really not caring about it to I can't wait to go to [BMI]. I'm trying to see my people. For that little bit, I don't feel like I'm at a PWI anymore. And that's really nice.

In the above quote Nathaniel, a participant from the treatment group, recalled his experience within the BMI and Black spaces on campus in a way that is in direct contrast to Brian. While Brian found himself on the outside looking in, Nathaniel referred to the BMI and the Black Culture Center (BCC), a physical space that is central to the Black community on campus, as a "home away from home." Through the BMI, which met for its class meetings in the BCC and was designed by BCC staff, participants were given access to the Black community that other Black students did not feel privy to. This sociocultural capital allowed them to forge supportive relationships sooner and feel comfortable in their transition into college. Jet cited this experience as one that fostered a sense of belongingness for him. "I think getting my sense of belonging, knowing people, getting to know people, being part of something bigger than yourself, and increasing the sphere of people you know and opportunities that you can be part of. I feel like it just made me feel more belonging in the [University] community, especially in the Black [University] community." While Jet talked about his sense of belonging at the university increasing, he went on to specify why and where this feeling came from.

I think most of the people I interact with and who I would call my friends or acquaintances are part of Black [University]. So I feel like almost slowly, not all the way but-- because I know white people too. I'm cool with white people too. I think almost slowly, I think I am part of Black [University] just by being black and just being what I-- interacting what I am involved in falls, I would say, within 
that realm. So yeah, I would say there is definitely a difference. I feel like I am more part of Black [University] than I am the rest of the [University] community, I would say.

Here Jet emphasized and identified a distinction between his sense of belonging in the greater university community and his sense of belonging in the Black community. MoFeezy furthered this sentiment by explicitly juxtaposing the greater university community and the BMI.

I almost didn't necessarily think of [BMI] as a part of the [University]. Even though that doesn't make sense, because it definitely is. But they felt very different. Like when you walk out of the BCC, it's just different. It's completely different.....So it didn't really impact my sense of belonging at [University]. I would see the students that were in $[\mathrm{BMI}]$ outside of the classroom, and we would speak and everything like that, and we'd hang out every now and then. But it still felt like we were all separated from the broader [University]. Like this is [BMI], and the [University] is over here. And the students that are in $[\mathrm{BMI}]$ go to [University].

The sentiments shared by Jet and MoFeezy were supported by the quantitative data that did not demonstrate a significant difference between groups relating to participants' sense of belonging to the university. It should also be noted that participants in the treatment group also discussed a sense of status or clout within the Black community on campus that allowed them access to additional support or resources. Matthew described feeling like upperclassmen and previous cohorts of the BMI were seeking him out to give him information and resources. "it makes it easier when you 
have-- as soon as you're-- okay, you're [BMI] this, '23, '24, whatever. Now you have people who are ahead of you who are wanting to pay it forward and help you out with different things and that were willing to talk to you and willing to help you."

To summarize, participants in the BMI discussed unique access and notoriety within the Black community on campus. MoFeezy captured this access to socio-cultural capital as he discussed his experience.

The thing about $[\mathrm{BMI}]$ is it's almost like-- I hate to put it this way, but it's almost like a title. Like, yeah, I was in $[\mathrm{BMI}]$ and you weren't. You know what I mean? And you walk around and you meet other students, and they'll say, yeah, you're in [BMI], right? I'm like, I didn't even know the student. But he knows I'm in [BMI]. And he'll be like in the cohort ahead of me, or something like that. Those kind of small differences, it kind of matter. Because it almost turns into sort of weird hierarchical social standing, that like it or not, that's kind of how it is. And then there were the students who weren't in [BMI], and they don't necessarily know as many students in the Black community. I'll use MBWI here. I know a lot of females on campus that aren't or are that Black, and they won't know a lot of people within the Black community. Because they'll say, well, I'm not in this, I'm not in this, I'm not in this. And so they don't know nobody.

Here he talks about his status within the community and his network within the community while also acknowledging it as a privilege that other Black students do not necessarily have access to. MoFeezy's statements provided insight into the experience of participants in the BMI and their access to socio-cultural capital on campus.

\section{Identity Development}


As participants recalled their experience, they each discussed different ways in which they felt their identities change over the course of their first year of college. Many made mention of the racialized campus experience as a factor that influenced their identity development, but they also referenced several other factors. As such, three subdomains were identified as ways by which participants experienced a sense of identity development: (1) Experiential Learning, (2) Formal Education, and (3) Intersectionality.

Experiential Learning. Across both groups, treatment and control, participants discussed merely existing as Black men on campus as an educational experience about their racial identity. They talked about observing how others responded to them in different spaces as well as learning more about themselves and their racial identity by simply being amongst other Black students. In phase I it was revealed that participants in the treatment group experienced greater variability in their Anti-White rating over the course of the year. When asked about the increase from baseline to the midpoint, Brian stated the following:

I guess it wasn't necessarily a hatred for all white people. It was more like every time I interacted with a white person or I was in a room alone with him, I was constantly thinking, "Oh, this person might be racist, or they might be making fun of my skin color in their head, but nice to me in my face." That's the feeling I get. That's what I think of when I think of anti-white in terms of myself.

Prior to this statement, Brian shared that the experience of being in a predominately White space was foreign to him, particularly one with racial division and tensions. Thus, his adjustment was to be wary of the White people he interacted with. Other participants from the treatment group discussed their proximity to the Black 
community as a factor that fostered their own racial identity. MoFeezy expressed that he felt "blacker" after his first year of college. When asked what made him feel this way he replied "Really the main thing is just hanging out around more Black individuals, where I can let that part of myself out. And the more you expose yourself to different things, or even different parts of yourself, the more you're going to become that. So I'd say that's what made the main difference, was having an outlet." Brian discussed how being amongst the Black community on campus helped him reject notions of internalized racism.

the internalized stereotypes, was definitely-- it was something that I struggled with coming here, but after spending a year here, I can definitely say that I don't really struggle with that as much or at all just because being a part of a black community and being around like so many pro-black people, I guess, which isn't a big thing where I come from, was like really positive to me and how I see myself and how I see other black people, too.

He went on to describe a sense of pride in Blackness held by the Black community on campus and he described this pride as contagious. In essence, the Black community on campus taught him a new appreciation for his own racial identity. To summarize, many participants described experiences, both positive and negative) that taught them about their own racial identity outside of the classroom.

Formal Education. Participants in the treatment group discussed the unique experience of having class material that resonated with their racial identity. Specifically, they mentioned the scheduled topics for instruction/discussion within the BMI 
intervention. Ray talked about how discussions from the BMI influenced his own selfreflection.

I got to $[\mathrm{BMI}]$ and it was different because I had gone through the syllabus, read it, and it was, this all seems like stuff that I have already learned...... It's like when you know of something that impacts you, you should know probably the most about it. And I didn't realize that until [BMI] started those conversations. It was something like, "Oh, how does masculinity affect the black community?" And they just go, "Oh well. There's some level of toxic masculinity but it doesn't really impact everyone the same way." Instead of really going deep into that conversation-- there is definitely toxic masculinity within the community. It affects everyone differently. But what matters the most is how it affects you personally and that started those conversations

In this quote, Ray presented the example of masculinity in the Black community as a topic discussed during the class period that influenced his process of self-reflection on his own identity. He also mentioned that there were a number of topics on the syllabus that were relevant to his identity and alluded to the discussions deepening his knowledge of topics he thought he understood. Similarly, Nathaniel reflected on how a class discussion on Blackness influenced how he saw his own Black identity.

I felt like I was allowed or admitted almost rather to take pride and joy and more stake in being black. And I really just came to claim it. Because before, I was like I'm a person and I don't really like claiming to be an American because I think America is kind of lame, but I saw other people that seemed more invested or blacker than me because they grew up around a bunch of black people or they did 
something more typical like play jazz or liked contemporary rap music when I like Grandmaster Flash and the Furious Five. That's my group. So I kind of felt out of place. And then, I realized I just had a small scope of what it means to be black in America. And [BMI] kind of opened it up to me and I was like, "Well, this isn't black." Like, "This is black. Black's expansive. Black is large. Black is different. Black is unique." It's almost like a guaranteed part of black culture is recognizing the individual and the community simultaneously. And figuring that out, that you've got to be unique to be black and being unique is like part of what makes you the community because the community is unique, and that unifying element, that weird, dualistic nature is really what made me feel a part of it. Prior to class discussion in the BMI, Nathaniel was not sure about his fit into Black culture. The BMI taught him to reimagine Blackness in a way more complex than the monolithic perception he previously held. The curriculum seemed to foster the identity development of many participants in the BMI.

Intersectionality. Participants also discussed intersectional experience both in and out of class that influenced their identity development. Nathaniel talked about a process of self-reflection on his experience as a Black man on campus.

Not particularly. It's something that I'm not especially versed or maybe just prepared to talk about it this time is what it's like to be a dude on campus. Like just being a male. Just being a guy on campus, I think, you start to recognize power dynamics. Like when I walk my friends that are girls back to class after a late exam or I come and pick them up when they get out of their night classes. To me, it's 2:00 am and I'll walk 2 miles across campus, no problem. The only 
problem is if it's long. And since it is [University] Black Men's Initiative, I think maybe more considerations of what it's like to be a male on campus. And if you become aware of that, for better or for worse, would be something to think about. In this statement Nathaniel is not only reflecting on his privilege and perceived role as a man on campus but he also seems to be critical of the BMI curriculum. In contrast, Ray was noted above using an example of a class discussion on masculinity to reflect on his own process of identity development. Additionally, Matthew mentioned class discussions on masculinity, "in [BMI], there is a lot of topics that we talked about that I never really went into detail with. It was, like, masculinity, talking about that a lot. But yeah. That was something that I really kind of ran with.” Lastly, class syllabi also indicated that the BMI facilitated several discussions on the intersection between race and masculinity as well as the Big 8 social identities: Race, Ethnicity, sexual orientation, gender identity, ability status, religion/spirituality, nationality, and socioeconomic status (Johnson, 2006). 


\section{CHAPTER V}

\section{Discussion}

The current study employed an explanatory mixed methods approach to evaluate an established Black Men's Initiative (BMI) on the campus of a predominately White institution (PWI). The research questions were designed to capture the impact of the BMI on the academic related outcomes, interpersonal factors, racial identity, and overall experience of Black male, first-year, college students. Quantitative results indicated that the BMI intervention did not have a significant impact on academic related variables, academic achievement and retention, nor was there a significant impact on the interpersonal variables measured. However, there was a statistically significant difference on one particular stage of Black racial identity development. Specifically, participants who were enrolled in the BMI experienced greater variability over time in their feelings associated with the Immersion-Emersion Anti-White stage of Cross's Black racial identity development model (Cross, 1995). Additionally, after interviewing 9 participants (treatment $n=6$; control $n=3$ ) about their experience, three overarching themes emerged from the qualitative data: (1) COVID-19, (2) Access, and (3) Identity Development. The discussion below will connect these findings with the previous scholarly literature and provide explanation and context for the findings of the study.

As previously mentioned, the 2019-2020 academic year was and will historically be an anomaly because of the impact of the COVID-19 pandemic. Participants spoke about a myriad of issues presented by the pandemic and its impact on their first-year experience. Many concerns mentioned were consistent with those discussed in recent literature: decreased engagement (Daniels, Goegan, \& Parker, 2021), lower motivation 
(Al-Kumaim, et al., 2021), mental health concerns (Pfefferbaum \& North, 2020), and concerns about wellness (Prime, Wade, \& Brown, 2020). However, participants also disclosed many difficult experiences with missed opportunities within their first year of college. While they mentioned missing chance for employment or even spring events, much of participants discussed was missing out on the social experience of their spring semester. This adds to the literature because it was not merely the isolating experience of social distancing but rather participants described this experience with a sense of grief. Participants seemed to put a significant amount of hope into the idea fostering depth in their social relationships during the spring semester and they seemed to grieve relationships that could have been.

Regarding academic achievement and retention of Black men at a PWI, quantitatively the BMI made no statistical impact. As previously mentioned, this may be due to impact of the COVID-19 pandemic or the limited sample size that did not provide enough statistical power to detect subtle differences. What has yet to be mentioned or examined is the question of the BMI's impact on academic achievement or retention. Qualitatively, participants cited the BMI as a supportive space academically due to the mandatory study hall and accountability in the form of one-on-one meetings with the program director. The support discussed by participants in this study is similar to the findings from Brooms's (2018) study on similar BMI programs across the country. In this study he suggested that programs such as the one evaluated by the current study provide a sense of holistic support. However, it does not appear that this support enhanced the academic performance or retention of students in the BMI. 
Interpersonal factors such as belonging, mattering, and self-efficacy were also assessed in both phases of the study. Quantitatively, there was no statistical difference between the treatment and control group. Qualitative analysis suggest that participants experienced a sense of belongingness and felt like they mattered more as a result of the BMI. These findings are not necessarily in contradiction of one another as the qualitative findings are based solely on the perception and report of participants while the quantitative findings are in comparison to a control group. Essentially, students in the BMI felt like they belonged and mattered but not more than their counterparts. Further, it is important to consider the context of participants' sense of belonging and mattering. Qualitative analysis provided insight into this matter as participants discussed feeling a sense of belongingness and mattering to the BMI and the Black community on campus as opposed to the university at large. Brooms's (2018) study suggests that BMIs promote a sense of belonging and mattering on campus; while the findings of the current study do not directly contradict this position, rather they provide nuance and specifics to that sense of belonging and mattering. Several participants made a clear distinction between their feelings toward the general university community and feelings for the Black community. These findings support The Belonging Hypothesis as Baumesiter and Leary (1995) argued that the need to belong can be satiated by one domain. Participants were made to feel so secure within the BMI and the Black community that they did not feel the need to pursue a sense of belonging to the University.

Regarding racial identity development, participants in the BMI had significantly different experiences than those in the control group within the Immersion-Emersion Anti White stage of Cross's (1995) model. The variability experienced by students enrolled in 
the BMI is consistent with the experience theorized by the Nigrescence model where Cross (1995) suggests that as individuals begin to educate themselves on their own Black racial identity, they may embrace anti-white sentiments that will later decrease as the individual continues their growth. This suggests that the BMI is facilitating the growth of its students' Black racial identity just as theorized by Cross's (1995) model. Phase I of the study did not yield any other significant differences between the racial identity development of students in the BMI when compared to the control group. Phase II of the study suggests that students in the BMI experienced greater opportunity for identity development than their counterparts in the control group through their access to the Black community and access to curriculum designed to speak to their intersectional identities.

When considering the results of the current study all together, the salient points are the qualitative findings that reveal the points of access for students in the BMI and how that also influences their identity development and other interpersonal variables. The themes drawn from the data tie directly to Museus's (2014) theory of Culturally Engaging Campus Environments (CECE) and Strayhorn's (2019) model of belonging in higher education.

In his work, Museus (2014) identifies several factors of CECEs: cultural familiarity, culturally relevant knowledge, cultural community service, opportunities for meaningful cross-cultural engagement, collectivist cultural orientations, culturally validating environments, humanized educational environments, proactive philosophies, and the availability of holistic support. Participants shared experiences that captured much of the criteria listed above. Specifically, participants discussed experiences of cultural familiarity in their connection within the Black community on campus, culturally 
relevant knowledge that they were exposed to through the BMI curriculum, culturally relevant community service through many events planned for BMI students, culturally validating environments and humanized educational environments within the BMI itself, and holistic support in the form of the support provided by the leadership team of the BMI. In this model, Museus (2014) suggested CECEs promote individual influences (belongingness, academic dispositions, and academic performance), which also translates into successful outcomes.

Strayhorn (2019) suggested similar ideas in his theory of belonging for college students; however, he contextualizes the experience with a bit more nuance. Strayhorn (2019) suggests the need to belong becomes increasingly more important in certain contexts, in certain times, and for certain groups. He also asserts that belongingness is impacted by social identity; specifically, intersecting identities. Findings from the current study suggest the BMI is serving intersectional identities of its students and attempting to foster a sense of belonging at an important transitional period, students' first year of college. Strayhorn (2019), like Museus (2014), suggests that factors such as those stated above should foster students' sense of belonging and in turn influence academic success.

The quantitative results introduce a conundrum for the theories of Museus (2014) and Strayhorn (2019). Trends in the means suggest that students in the BMI rated higher on all interpersonal factors, except for belongingness and mattering. As previously mentioned, these results also challenge the findings of Brooms (2018) study on BMIs where he concluded that BMIs foster a sense of belonging to the university. Given the nuance expressed by participants regarding how and where they experienced a sense of belonging, the findings of the current study are best understood as contextual when 
considering belonging and mattering specifically. While Strayhorn (2019) suggests belonging is important in certain contexts, the results to the current study further this notion by suggesting that belonging occurred within a specific context (i.e., the Black community) without necessarily being translated to the university at large. As such, it can be concluded that the BMI under review fostered a sense of belongingness to the Black community on campus by providing students with unique access to the community.

This connection between racial identity and sense of belonging is similar to the commitment and attachment aspect of Phinney's (2005) theory of ethnic identity. This is described as the strong attachment and investment in a group based on one's ethnic identity (Phinney \& Ong, 2007). This theoretical concept has some connection to construct of belongingness but also some key differences. Similarly, they are both based on social connection with others. In contrast, belongingness is based on frequent personal contact with others and the need to perceive an ongoing relationship (Baumeister \& Leary, 1995), while commitment and attachment are constructs based on how one identifies themselves in relation to others (Phinney \& Ong, 2007). Further, Phinney’s (2005) theory does not quite capture the findings of the current study because it also does not account for the sense of belonging within the context of both race and community. In the context of the current study, community is the Black community on the college campus.

Bronfenbrenner's (1977) ecological systems theory presents another way to conceptualize the findings of the current study. Specifically, Allen, Vella-Brodrick, and Waters (2016) adapted Brofenbrenner's ecological systems theory to a model of school belongingness. They suggest that school belongingness is fostered through a student's 
interaction with different layers of a larger system. The student level includes interpersonal factors such as emotional functioning, personal demographics, and academic motivation. The microsystem includes factors that are based on individual relationships such as teacher support, peer support and family support. They describe the mesosystem as a the "byproduct of the interactions among the layers" (Allen et al., 2016, p. 109). In essence, the mesosystem seems to capture the experience students may have on campus, including but not limited to "school processes, practices, policies, and pedagogy" (Allen et al., 2016, p. 109). This would also include extracurricular activities as well. The exosystem consists of the community surrounding the institution, including extended family, neighborhood, school board, etc. The macrosystem is a broader level that includes legislation and policies from a federal level as well as cultural and historical contexts of the specific school. One of the shortcomings of this theoretical model is that it does not explicitly address the issue of race at each identified layer, rather it alludes to race at the individual and macrosystem level.

If this ecological model were adapted to school belongingness at the collegiate level, the BMI program evaluated by the current study would likely fall into the microsystem layer, based on participant interviews as well as general descriptions of the program. Further, the Black community at the university would likely fall into the exosystem while the mesosystem and macrosystem would include factors such as the administration and historical context of the university, respectively. In this particular conceptualization, the belongingness experienced by participants is fulfilled at the microsystem level and partially fulfilled at the ecosystem level. This suggests that the BMI demonstrates a strength in developing individual relationships that translate into 
sociocultural capital that allows them to establish a sense of belonging within the Black community, or a developing sense of belonging at the exosystem level. Participants did not explicitly address the meso and macrosystem layers when describing factors that influenced their sense of belongingness; however, some participants expressed feeling like the university did not care about them as a student or as an individual. Given the history of racism within the university and the country as a whole it is not surprising that participants' sense of belonging did not extend beyond the exosystem. Future research should examine barriers to belongingness at different levels of the school system and the broader society.

It should be noted that while the BMI provides unique access to its students, this access is also one of the missteps of the program. The BMI suggests that it admits students based on perceived needs; however, quantitative analysis of group differences suggests that the application process is merit-based. The reported high-school GPAs and percentage of students who received scholarships in the BMI suggests that the BMI seeks out what Amechi and colleagues (2016) identified as "college achievers and student leaders" (p.102). While the identities of these students are underrepresented on college campuses and are still in need of individualized attention, the demographic attributes of participants in the BMI suggest that these students were already primed for success. This is not an argument suggesting high achieving Black male students should not receive intervention, rather it is suggesting the application process to the BMI is biased toward merit as opposed to need. Further, the exclusivity of the program introduces a social hierarchy from which students in the BMI benefit and others are left on the outside looking in. This presents an argument to extend programming such as the BMI under 
review in order to reach more students and provide them similar forms of access to community.

In conclusion, the BMI evaluated by the current study did not have a statistical impact on students' academic, interpersonal, or racial development; however, the program did have an impact on their overall campus experience. The BMI provided them with access to the support and curriculum that influenced their sense of identity. Most importantly, the BMI provided them with access to community which fostered a sense of belonging that was specific to the Black community on campus as opposed to the university at large. This suggests a sense of belonging that is both racialized and localized. In essence, programs such as the BMI studied are important to underrepresented populations on campus, because they create social connection and foster access into specific communities. Many of the findings from the current study can be connected to previous literature; however, the study offers new insights for the experience of a belonging in higher education that lie specifically at the intersection of ecological systems and race.

\section{Limitations}

As mentioned several times, the current study was significantly impacted by the COVID-19 pandemic and its pervasive influence of life itself as well as the specific impact on the collegiate experience. Additionally, the director of the current study missed a significant portion of the fall semester altering the course schedule and changing the timing of certain events. As such, it is difficult and even inappropriate to make generalizations about the BMI program based on the data collected for the current study. 
Rather the results based on the data should be used to understand the program within the context of this specific and unique academic year.

Additionally, limited sample size and the significant attrition of participants throughout the course of the study is a significant limitation of the current study as it limits the statistical power of the qualitative analysis. While the impact of COVID-19 on student motivation and engagement is a possible explanation for the $72.3 \%$ attrition rate, the length of the survey should also be considered as an influencing factor.

Lastly, the measures used to assess belongingness and mattering were designed to measure those constructs within the context of the university as opposed to specific cultural context. The quantitative analysis was limited to understanding the feelings of participants toward the university at large and did not capture the cultural experience of belonging to the Black community. Future studies should include measures of belonging and/or mattering that are culturally specific.

\section{Implications}

The current study adds to an existing body of literature for Black males in higher education. Specifically, these results provide insight to the emotional and academic resilience of Black men in the face of adversity, and the power of cultural communities on the transition into college. Additionally, the current study informs future research on BMIs, racial identity, and belongingness.

Given the influence of COVID-19 on participants in the current study, results provide implications for the academic and mental well-being of Black male college students. Participants shared their difficulties with adjusting in unprecedented times and explicitly mentioned disengaging, checking out, and losing motivation and focus. 
Additionally, students expressed feelings of anxiety about the virus and grief regarding the many opportunities they missed out on. As such, these findings imply that academic support staff and mental health staff should increase outreach during times of campus adversity. Additionally, staff should be mindful not just of the academic impact of an event like a global pandemic but the impact and grief of lost social interactions. Lastly, this study captures stories of both intrinsic resilience in the form of identifying an issue and correcting it, as well as stories about the power of support from others. These findings can be used by academic advisors and mental health staff on college campuses to inform them of the resilience of Black male students and the ability to self-correct issues.

Additionally, these findings can be used by university administrators to understand the power of community on campus and the factors that seem to influence the access to specific communities. The BMI evaluated by the current study provided its students with access and status within a cultural community on campus. Participants discussed this access as helping them connect socially and helping them navigate their first year of college while students not enrolled in the BMI found themselves facing more pitfalls. Hopefully, these results provide insights that further the understanding of identity and community on college campuses to existing notions that being Black means having access to the Black community on campus. These findings highlight the importance of cultural spaces and programming at PWIs and can be used by administrators to expand programming such as BMIs that provide unique access to cultural communities. In short, these results provide rationale for administrators to not just continue institutional support of initiatives like the BMI studied but increase further financial support so the BMI can extend their access to others. 
Finally, these findings present implications for future research on Black male students. As previously mentioned, researchers should seek to understand the contextual experience of belongingness as it relates to specific and cultural communities. Future research should also examine school belongingness within higher education as it relates to the ecological systems theory (Bronfenbrenner, 1977; Allen, Vella-Brodrick, \& Waters, 2016). Special consideration should be given to the barriers to belongingness; specifically, for students of color at PWIs. 


\section{REFERENCES}

Allen, K. A., Vella-Brodrick, D., \& Waters, L. (2016). Fostering school belonging in secondary schools using a socio-ecological framework. The Educational and Developmental Psychologist, 33(1), 97-121.

Anderman, E. M. (2002). School effects on psychological outcomes during adolescence. Journal of Educational Psychology, 94(4), 795-809. doi: 10.1037//00220663.94.4.795

Bacharier, G. (2020, May 29). UM System, local police address Minneapolis police killing of George Floyd. Columbia Missourian. https://www.columbiamissourian.com/news/local/um-system-local-policeaddress-minneapolis-police-killing-of-george-floyd/article_32ce3d2e-a13d-11eaaf13-0f3807eea22b.html.

Bacharier, G. (2020, May 29). UPDATE: Snapchat video reported to MU Title IX, receives viral backlash. Columbia Missourian.

https://www.columbiamissourian.com/news/higher_education/update-snapchatvideo-reported-to-mu-title-ix-receives-viral-backlash/article_87e67468-a1e511ea-abe8-ebd03c1ecebd.html.

Baier, S. T., Markman, B. S., \& Pernice-Duca, F. M. (2016). Intent to persist in college freshmen: The role of self-efficacy and mentorship. Journal of College Student Development, 57(5), 614-619.

Bandura, A. (1977). Self-efficacy: toward a unifying theory of behavioral change. Psychological Review, 84(2), 191. 
Bandura, A. (1989). Human agency in social cognitive theory. American Psychologist, 44(9), 1175.

Bandura, A. (1994). Self-efficacy. In V. S. Ramachaudran (Ed.), Encyclopedia of human behavior (Vol. 4, pp. 71-81). New York: Academic Press. (Reprinted in H. Friedman [Ed.], Encyclopedia of mental health. San Diego: Academic Press, 1998).

Baldwin, J. A. (1981). Notes on an Africentric theory of Black personality. The Western Journal of Black Studies, 5(3), 172.

Baldwin, J. A. (1984). African self-consciousness and the mental health of AfricanAmericans. Journal of Black Studies, 15(2), 177-194.

Barz, M., Lange, D., Parschau, L., Lonsdale, C., Knoll, N., \& Schwarzer, R. (2016). Selfefficacy, planning, and preparatory behaviours as joint predictors of physical activity: a conditional process analysis. Psychology \& health, 31(1), 65-78.

Baumeister, R. F., \& Leary, M. R. (1995). The need to belong: desire for interpersonal attachments as a fundamental human motivation. Psychological bulletin, 117(3), 497.

Betz, N. E. (1992). Counseling uses of career self-efficacy theory. The Career Development Quarterly, 41(1), 22-26.

Bonner, F. A., \& Bailey, K. W. (2006). Enhancing the academic climate for African American men. African American men in college, 24-46.

Brenner, S., Muula, A. S., Robyn, P. J., Bärnighausen, T., Sarker, M., Mathanga, D. P., ... \& De Allegri, M. (2014). Design of an impact evaluation using a mixed methods model-an explanatory assessment of the effects of results-based financing 
mechanisms on maternal healthcare services in Malawi. BMC health services research, 14(1), 180.

Bronfenbrenner, U. (1979). The ecology of human development. Harvard university press.

Buck, H. G., Dickson, V. V., Fida, R., Riegel, B., D’Agostino, F., Alvaro, R., \& Vellone, E. (2015). Predictors of hospitalization and quality of life in heart failure: A model of comorbidity, self-efficacy and self-care. International journal of nursing studies, 52(11), 1714-1722.

Bullock-Yowell, E., Andrews, L., \& Buzzetta, M. E. (2011). Explaining career decisionmaking self-efficacy: Personality, cognitions, and cultural mistrust. The Career Development Quarterly, 59(5), 400-411. Retrieved from http://proxy.mul.missouri.edu/login?url=https://search.proquest.com/docview/894 $\underline{273243 \text { ?accountid }=14576}$

Butler, S. K., Evans, M. P., Brooks, M., Williams, C. R., \& Bailey, D. F. (2013). Mentoring African American men during their postsecondary and graduate school experiences: Implications for the counseling profession. Journal of Counseling \& Development, 91(4), 419-427.

Cartwright, A. N. (2019, April 29). Dr. Kevin McDonald Accepts Position at UVA. Division of Inclusion, Diversity \& Equity. https://diversity.missouri.edu/2019/vice-chancellor-kevin-mcdonald-acceptsposition-at-uva/.

Chavous, T. M., Bernat, D. H., Schmeelk-Cone, K., Caldwell, C. H., Kohn-Wood, L., \& Zimmerman, M. A. (2003). Racial identity and academic attainment among African American adolescents. Child development, 74(4), 1076-1090. 
Chemers, M. M., Hu, L. T., \& Garcia, B. F. (2001). Academic self-efficacy and first year college student performance and adjustment. Journal of Educational psychology, 93(1), 55.

Choi, M. (2020, June 1). June 1, 2020: Combatting discrimination and racism. Office of the President. https://president.missouri.edu/news/june-1-2020-combattingdiscrimination-and-racism/.

Choi, N. (2005). Self-efficacy and self-concept as predictors of college students' academic performance. Psychology in the Schools, 42(2), 197-205.

Coffman, D. L., \& Gilligan, T. D. (2002). Social support, stress, and self-efficacy: Effects on students' satisfaction. Journal of College Student Retention: Research, Theory \& Practice, 4(1), 53-66.

Creswell, J. W., \& Clark, V. L. P. (2017). Designing and conducting mixed methods research. Sage publications.

Cross Jr, W. E., \& Vandiver, B. J. (2001). Nigrescence theory and measurement: Introducing the Cross Racial Identity Scale (CRIS).

Cross Jr, W. E., "The Negro-to-Black conversion experience." Black world 20, no. 9 (1971): 13-27.

Cross, W. E., Jr. (1995). The psychology of nigrescence: Revising the Cross model. In J. G. Ponterotto, J. M. Casas, L. A. Suzuki, \& C. M. Alexander (Eds.), Handbook of multicultural counseling (pp. 93-122). Sage Publications, Inc.

Cross, W. E., Jr., \& Vandiver, B. J. (2001). Nigrescence theory and measurement: Introducing the Cross Racial Identity Scale (CRIS). In J. G. Ponterotto, J. M. 
Casas, L. A. Suzuki, \& C. M. Alexander (Eds.), Handbook of multicultural counseling (pp. 371-393). Sage Publications, Inc.

Curators of the University of Missouri 1997-2002. (2019, December 2). Significant Dates in the History of the University of Missouri. https://muarchives.missouri.edu/sigdates.html.

Daniels, L. M., Goegan, L. D., \& Parker, P. C. (2021). The impact of COVID-19 triggered changes to instruction and assessment on university students' selfreported motivation, engagement and perceptions. Social Psychology of Education, 24(1), 299-318.

Deci, E. L., \& Ryan, R. M. (1985). The general causality orientations scale: Selfdetermination in personality. Journal of research in personality, 19(2), 109-134. doi:10.1016/0092-6566(85)90023-6

DeWitz, S. J., \& Walsh, W. B. (2002). Self-efficacy and college student satisfaction. Journal of Career Assessment, 10(3), 315-326.

DeWitz, S. J., Woolsey, M. L., \& Walsh, W. B. (2009). College student retention: An exploration of the relationship between self-efficacy beliefs and purpose in life among college students. Journal of College Student Development, 50(1), 19-34.

Ferguson, A. A. (2010). Bad boys: Public schools in the making of black masculinity. University of Michigan Press.

Freeman, T. M., Anderman, L. H., \& Jensen, J. M. (2007). Sense of belonging in college freshmen at the classroom and campus levels. The Journal of Experimental Education, 75(3), 203-220. 
Gangadharbatla, H. (2008). Facebook me: Collective self-esteem, need to belong, and internet self-efficacy as predictors of the iGeneration's attitudes toward social networking sites. Journal of interactive advertising, 8(2), 5-15.

Gipson, M. D. (2020, August 10). Introducing Vice Chancellor Gipson. Division of Inclusion, Diversity \& Equity. https://diversity.missouri.edu/2020/introducing-drgipson/.

Glaser, B. G. (1965). The constant comparative method of qualitative analysis. Social problems, 12(4), 436-445.

Gloria, A. M., \& Hird, J. S. (1999). Influences of ethnic and nonethnic variables on the career decision-making self-efficacy of college students. The Career Development Quarterly, 48(2), 157-174. Retrieved from http://proxy.mul.missouri.edu/login?url=https://search.proquest.com/docview/219 426137 ? accountid=14576

Goodenow, C., \& Grady, K. E. (1993). The relationship of school belonging and friends' values to academic motivation among urban adolescent students. Journal of Experimental Education, 62(1), 60-71. doi:10.1080/00220973.1993.9943831

Gordon, D. M., Iwamoto, D., Ward, N., Potts, R., \& Boyd, E. (2009). Mentoring urban Black Middle-School Male Students: Implications for Academic Achievement. The Journal of Negro education, 78(3), 277-289.

Gore Jr, P. A., Leuwerke, W. C., \& Turley, S. E. (2005). A psychometric study of the College Self-Efficacy Inventory. Journal of College Student Retention: Research, Theory \& Practice, 7(3), 227-244. 
Guiffrida, D. A. (2006). Toward a cultural advancement of Tinto's theory. The Review of Higher Education, 29(4), 451-472. doi:10.1080/00220973.1993.9943831

Guiffrida, D. A., Lynch, M. F., Wall, A. F., \& Abel, D. S. (2013). Do reasons for attending college affect academic outcomes?: A test of a motivational model from a self-determination theory perspective. Journal of College Student Development, 54(2), 121-139. doi:10.1353/csd.2013.0019

Gushue, G. V. (2006). The relationship of ethnic identity, career decision-making selfefficacy and outcome expectations among Latino/a high school students. Journal of Vocational Behavior, 68(1), 85-95.

Gustafsson, M., \& Borglin, G. (2013). Can a theory-based educational intervention change nurses' knowledge and attitudes concerning cancer pain management? A quasi-experimental design. BMC health services research, 13(1), 328.

Hackett, G., \& Betz, N. E. (1981). A self-efficacy approach to the career development of women. Journal of Vocational Behavior, 18(3), 326-339.doi:10.1016/00018791(81)90019-1

Halpern, E. S. (1983). Auditing Naturalistic Inquiries: Some Preliminary Applications. Part 1: Development of the Process. Part 2: Case Study Application.

Harper, S. R. (2009). Niggers no more: A critical race counternarrative on Black male student achievement at predominantly White colleges and universities. International Journal of Qualitative Studies in Education, 22(6), 697-712. 
Harper, S. R. (2012). Black male student success in higher education: A report from the National Black Male College Achievement Study. University of Pennsylvania, Graduate School of Education, Center for the Study of Race and Equity in Education.

Harper, S. R. (2015). Black male college achievers and resistant responses to racist stereotypes at predominantly White colleges and universities. Harvard Educational Review, 85(4), 646-674.

Harper, S. R., \& Quaye, S. J. (2007). Student organizations as venues for Black identity expression and development among African American male student leaders. Journal of College Student Development, 48(2), 127-144.

Harper, S. R., Williams, C. D., \& Blackman, H. W. (2013). Black male student-athletes and racial inequities in NCAA Division I college sports. Philadelphia: University of Pennsylvania, Center for the Study of Race and Equity in Education.

Harris III, F., Palmer, R. T., \& Struve, L. E. (2011). " Cool posing" on campus: A qualitative study of masculinities and gender expression among Black men at a private research institution. The Journal of Negro Education, 47-62.

Harvey, A. R., \& Hill, R. B. (2004). Africentric youth and family rites of passage program: Promoting resilience among at-risk African American youths. Social Work, 49(1), 65-74.

Hausmann, L. R., Schofield, J. W., \& Woods, R. L. (2007). Sense of belonging as a predictor of intentions to persist among African American and White first-year college students. Research in higher education, 48(7), 803-839. 
Hausmann, L. R., Ye, F., Schofield, J. W., \& Woods, R. L. (2009). Sense of belonging and persistence in White and African American first-year students. Research in Higher Education, 50(7), 649-669. doi:10.1007/s11162-009-9137-8

Hoffman, M., Richmond, J., Morrow, J., \& Salomone, K. (2002). Investigating "sense of belonging" in first-year college students. Journal of College Student Retention: Research, Theory \& Practice, 4(3), 227-256.

Holt, M. K., \& Espelage D. L. (2003). A Cluster Analytic Investigation of Victimization Among High School Students: Are Profiles Differentially Associated with Psychological Symptoms and School Belonging? The Journal of Applied School Psychology, 19, 81-98. doi:10.1300/J008v19n02_06

Howard, T. C. (2014). Black male (d): Peril and promise in the education of African American males. Teachers College Press.

Hsieh, P., Sullivan, J. R., \& Guerra, N. S. (2007). A closer look at college students: Selfefficacy and goal orientation. Journal of Advanced Academics, 18(3), 454-476.

Hull-Blanks, E., Kurpius, S. E. R., Befort, C., Sollenberger, S., Nicpon, M. F., \& Huser, L. (2005). Career goals and retention-related factors among college freshmen. Journal of Career Development, 32(1), 16-30.

Ivankova, N. V., Creswell, J. W., \& Stick, S. L. (2006). Using mixed-methods sequential explanatory design: From theory to practice. Field methods, 18(1), 3-20.

Ivankova, N. V., \& Stick, S. L. (2007). Students' persistence in a distributed doctoral program in educational leadership in higher education: A mixed methods study. Research in Higher Education, 48(1), 93. 
Johnson, K. (2006). Resonance in an exemplar-based lexicon: The emergence of social identity and phonology. Journal of phonetics, 34(4), 485-499.

Jones, R., Holton, W., \& Joseph, M. (2019). Call Me MiSTER: A Black Male Grow Your Own Program. Teacher Education Quarterly, 46(1), 55.

Kambon, K. K. (2012). African/Black psychology in the American context: An Africancentered approach. Nubian Nation Publications. Tallahassee, FL

Kirk, G., \& Okazawa-Rey, M. (2006). Identities and social locations: Who am I? Who are my people?. American identities: An introductory textbook, 9-15.

Kiyama, J. M., Museus, S. D., \& Vega, B. E. (2015). Cultivating campus environments to maximize success among Latino and Latina college students. New Directions for Higher Education, 2015(172), 29-38.

Krishnan, S. S., \& Sitaraman, R. K. (2013). Video stream quality impacts viewer behavior: inferring causality using quasi-experimental designs. IEEE/ACM Transactions on Networking, 21(6), 2001-2014.

Kuperminc, G. P., Darnell, A. J., \& Alvarez-Jimenez, A. (2008). Parent involvement in the academic adjustment of Latino middle and high school youth: Teacher expectations and school belonging as mediators. Journal of Adolescence, 31(4), 469-483. doi:10.1016/j.adolescence.2007.09.003

Ladson-Billings, G. (2011). Boyz to men? Teaching to restore Black boys' childhood. In The Education of Black Males in a'Post-Racial'World. Race Ethnicity and Education, 1, 7-15. 
LaVant, B. D., Anderson, J. L., \& Tiggs, J. W. (1997). Retaining African American men through mentoring initiatives. New Directions for Student Services, 1997(80), 4353.

Lincoln, Y. S., \& Guba, E. G. (1985). Establishing trustworthiness. Naturalistic inquiry, 289, 331.

Ma, X. (2003). Sense of belonging to school: Can schools make a difference?. The Journal of Educational Research, 96(6), 340-349.

Mann, H. (1848). Twelfth annual report to the Massachusetts Board of Education. The republic and the school: Horace Mann and the education of free men.

Maslow, A. H. (1954). Motivation and Personality, New York: Harper

Mau, W. C. (2000). Cultural differences in career decision-making styles and selfefficacy. Journal of vocational behavior, 57(3), 365-378.

McElderry, J. A., Williams, J., Mayes, M., Gilliam, D. D., \& Taylor Jr, C. (2018). An Identity Development and Support Initiative for Black Men. Applying Student Development Theories Holistically: Exemplar Programming in Higher Education, 32.

Mcgraw, K., Moore, S., Fuller, A., \& Bates, G. (2008). Family, peer and school connectedness in final year secondary school students. Australian Psychologist, 43(1), 27-37. doi:10.1080/00050060701668637

McKinney, R. (2020, June 2). Incoming MU freshman who mocked Floyd killing rescinds enrollment. Columbia Daily Tribune. https://www.columbiatribune.com/story/news/education/2020/06/02/incomingmu-freshman-who-mocked-floyd-killing-rescinds-enrollment/113736690/. 
McNeely, C., \& Falci, C. (2004). School connectedness and the transition into and out of health-risk behavior among adolescents: A comparison of social belonging and teacher support. Journal of School Health, 74(7), 284-292. doi:10.1111/j.17461561.2004.tb08285.x

Museus, S. D. (2008). The role of ethnic student organizations in fostering African American and Asian American students' cultural adjustment and membership at predominantly White institutions. Journal of College Student Development, 49(6), $568-586$.

Museus, S. D. (2011). Generating Ethnic Minority Student Success (GEMS): A qualitative analysis of high-performing institutions. Journal of Diversity in Higher Education, 4(3), 147.

Museus, S. D. (2014). The culturally engaging campus environments (CECE) model: A new theory of success among racially diverse college student populations. In Higher education: Handbook of theory and research (pp. 189-227). Springer, Dordrecht.

Museus, S. D., Yi, V., \& Saelua, N. (2017). The impact of culturally engaging campus environments on sense of belonging. The Review of Higher Education, 40(2), $187-215$.

Newman, B. M., Newman, P. R., Griffen, S., O'Connor, K., \& Spas, J. (2007). The relationship of social support to depressive symptoms during the transition to high school. Adolescence, 42(167), 441-460.

Nobles, W. W. (1973). Psychological research and the Black self-concept: A critical review. Journal of Social Issues, 29(1), 11-31. 
Noguera, P. A. (2003). The trouble with Black boys: The role and influence of environmental and cultural factors on the academic performance of African American males. Urban education, 38(4), 431-459.

Office of the University Registrar. (2021). University GPA Averages. Office of the University Registrar. https://registrar.missouri.edu/grades-calculators/universitygpa-averages/.

Ogbu, J. U. (1987). Variability in minority school performance: A problem in search of an explanation. Anthropology \& Education Quarterly, 18(4), 312-334.

Padgett, D., Mathew, R., \& Conte, S. (2004). Peer debriefing and support groups. The qualitative research experience, 229-239.

Palmer, R., \& Gasman, M. (2008). " It takes a village to raise a child": The role of social capital in promoting academic success for African American men at a Black college. Journal of College Student Development, 49(1), 52-70.

Peterson, D. J. (2016). The flipped classroom improves student achievement and course satisfaction in a statistics course: A quasi-experimental study. Teaching of Psychology, 43(1), 10-15.

Pfefferbaum, B., \& North, C. S. (2020). Mental health and the Covid-19 pandemic. New England Journal of Medicine, 383(6), 510-512.

Phinney, J. S. (2005). Ethnic identity in late modern times: A response to Rattansi and Phoenix. Identity, 5(2), 187-194. 
Phinney, J. S., \& Ong, A. D. (2007). Conceptualization and Measurement of Ethnic Identity: Current Status and Future Directions. Journal of Counseling Psychology, 54(3), 271-281.

Pillay, Y. (2005). Racial identity as a predictor of the psychological health of African American students at a predominantly White university. Journal of Black Psychology, 31(1), 46-66.

Pittman, L. D., \& Richmond, A. (2008). University belonging, friendship quality, and psychological adjustment during the transition to college. The Journal of Experimental Education, 76(4), 343-362. doi:10.3200/JEXE.76.4.343-362

Pittman, L. D., \& Richmond, A. (2007). Academic and psychological functioning in late adolescence: The importance of school belonging. The Journal of Experimental Education, 75(4), 270-290. doi:10.3200/JEXE.75.4.270-292

Prime, H., Wade, M., \& Browne, D. T. (2020). Risk and resilience in family well-being during the COVID-19 pandemic. American Psychologist.

Ramos-Sánchez, L., \& Nichols, L. (2007). Self-efficacy of first-generation and non-firstgeneration college students: The relationship with academic performance and college adjustment. Journal of college counseling, 10(1), 6-18.

Rawlston-Wilson, V., Saavedra, S., \& Chauhan, S. (2014). From access to completion: A seamless path to college graduation for African American students. National Urban League, Washington Bureau. Retrieved from: https://cmsi.gse.upenn.edu/sites/default/files/National\%20Urban\%20League $\% 20$ $\underline{\text { Report.pdf }}$ 
Reid, K. W. (2013). Understanding the relationships among racial identity, self-efficacy, institutional integration and academic achievement of Black males attending research universities. The Journal of Negro Education, 82(1), 75-93.

Roberts-Douglass, K., \& Curtis-Boles, H. (2013). Exploring positive masculinity development in African American men: A retrospective study. Psychology of Men \& Masculinity, 14(1), 7.

Roe, D., Hasson-Ohayon, I., Mashiach-Eizenberg, M., Derhy, O., Lysaker, P. H., \& Yanos, P. T. (2014). Narrative enhancement and cognitive therapy (NECT) effectiveness: A quasi-experimental study. Journal of clinical psychology, 70(4), $303-312$.

Ross, S. I., \& Jackson, J. M. (1991). Teachers' expectations for Black males' and Black females' academic achievement. Personality and Social Psychology Bulletin, 17(1), 78-82.

Roth, B. B., Westrheim, K., Jones, L., \& Manger, T. (2017). academic self-efficacy, educational motives and aspects of the Prison sentence as Predictors for Participation in Prison education. Journal of Correctional Education (1974-), 68(3), 19-40.

Rowley, S. J., Sellers, R. M., Chavous, T. M., \& Smith, M. A. (1998). The relationship between racial identity and self-esteem in African American college and high school students. Journal of personality and social psychology, 74(3), 715.

Sanchez, B., Col’on, Y., \& Esparza, P. (2005). The role of sense of school belonging and gender in the academic adjustment of Latino adolescents. Journal of Youth and Adolescence, 34(6), 619-628. doi:10.1007/s10964-005-8950-4 
Schwarzer, R., \& Renner, B. (2000). Social-cognitive predictors of health behavior: action self-efficacy and coping self-efficacy. Health psychology, 19(5), 487.

Shochet, I. M., Smith, C. L., Furlong, M. J., \& Homel, R. (2011). A prospective study investigating the impact of school belonging factors on negative affect in adolescents. Journal of Clinical Child \& Adolescent Psychology, 40(4), 586-595. doi:10.1080/15374416.2011.581616

Skaalvik, E. M., \& Skaalvik, S. (2016). Teacher stress and teacher self-efficacy as predictors of engagement, emotional exhaustion, and motivation to leave the teaching profession. Creative Education, 7(13), 1785-1799.

Slaten, C. D., Elison, Z. M., Deemer, E. D., Hughes, H. A., \& Shemwell, D. A. (2018). The development and validation of the university belonging questionnaire. The Journal of Experimental Education, 86(4), 633-651.

Slaten, C. D., Elison, Z. M., Hughes, H., Yough, M., \& Shemwell, D. (2015). Hearing the Voices of Youth at Risk for Academic Failure: What Professional School Counselors Need to Know. The Journal of Humanistic Counseling, 54(3), 203220. doi:10.1002/johc. 12012

Slaten, C. D., Ferguson, J. K., Allen, K. A., Brodrick, D. V., \& Waters, L. (2016). School belonging: A review of the history, current trends, and future directions. The Educational and Developmental Psychologist, 33(1), 1-15.

Slaten, C. D., Yough, M. S., Shemwell, D. A., Scalise, D. A., Elison, Z. M., \& Hughes, H. A. (2014). Eat, Sleep, Breathe, Study: Understanding What It Means to Belong at a University From the Student Perspective. Excellence in Higher Education, 5(1), 1-5. doi: 10.5195/ehe.2014.117 
Smith, W. A., Hung, M., \& Franklin, J. D. (2011). Racial battle fatigue and the miseducation of Black men: Racial microaggressions, societal problems, and environmental stress. The Journal of Negro Education, 63-82.

Smith, E. P., Walker, K., Fields, L., Brookins, C. C., \& Seay, R. C. (1999). Ethnic identity and its relationship to self-esteem, perceived efficacy and prosocial attitudes in early adolescence. Journal of adolescence, 22(6), 867-880.

Solberg, V. S., O'Brien, K., Villareal, P., Kennel, R., \& Davis, B. (1993). Self-efficacy and Hispanic college students: Validation of the college self-efficacy instrument. Hispanic journal of behavioral sciences, 15(1), 80-95.

Soysa, C. K., \& Wilcomb, C. J. (2015). Mindfulness, self-compassion, self-efficacy, and gender as predictors of depression, anxiety, stress, and well-being. Mindfulness, 6(2), 217-226.

Stake, R. E. (1978). The case study method in social inquiry. Educational researcher, $7(2), 5-8$

Stake, R. E. (1995). The art of case study research. Thousand Oaks, California: Sage.

Strayhorn, T. L. (2019). College students' sense of belonging: A key to educational success for all students. NEW YORK: Routledge.

Strayhorn, T. L. (2008). Fittin'in: Do diverse interactions with peers affect sense of belonging for Black men at predominantly White institutions?. NASPA Journal, 45(4), 501-527.

Strayhorn, T. L., Blakewood, A. M., \& DeVita, J. M. (2008). Factors affecting the college choice of African American gay male undergraduates: Implications for 
retention. National Association of Student Affairs Professionals Journal, 11(1), 88-108.

Strayhorn, T. L., \& Mullins, T. G. (2012). Investigating Black Gay Male Undergraduates' Experiences in Campus Residence Halls. Journal of College \& University Student Housing.

Strayhorn, T. L., \& Saddler, T. N. (2009). Gender differences in the influence of facultystudent mentoring relationships on satisfaction with college among African Americans. Journal of African American Studies, 13(4), 476.

Strayhorn, T. L., \& Terrell, M. C. (2007). Mentoring and Satisfaction with College for Black Students. Negro Educational Review, 58.

Taylor, J., \& Grundy, C. (1996). Measuring black internalization of white stereotypes about African Americans: the Nadanolitization Scale. Handbook of tests and measurements of Black populations, 2, 217-226.

Taylor, K. M., \& Betz, N. E. (1983). Applications of self-efficacy theory to the understanding and treatment of career indecision. Journal of Vocational Behavior, 22(1), 63-81.doi:10.1016/0001-8791(83)90006-4

Tierney, W. G. (1992). An anthropological analysis of student participation in college. The Journal of Higher Education, 603-618. Retrieved from http://www.jstor.org/stable/pdf/1982046.pdf

Tinto, V. (1988). Stages of student departure: Reflections on the longitudinal character of student leaving. The Journal of Higher Education, 438-455. Retrieved from http://www.jstor.org/stable/pdf/1981920.pdf 
University of Missouri. (2020, September 30). Student Body Profile. Fall 2020 Student Body Profile. https://enrollment.missouri.edu/wp-content/uploads/2020/09/Fall2020-Student-Body-Profile-1.pdf.

U.S. News \& World Report. (2021). At These National Universities, Freshmen Are Most Likely to Return. U.S. News \&amp; World Report. https://www.usnews.com/best-colleges/rankings/national-universities/freshmenleast-most-likely-return.

Uwah, C. J., McMahon, H. G., \& Furlow, C. F. (2008). School belonging, educational aspirations, and academic self-efficacy among African American male high school students: Implications for school counselors. Professional School Counseling, 11(5), 2156759X0801100503.

VanDelinder, E. (2015, November 7). Racial climate at MU: A timeline of incidents in fall 2015. Columbia Missourian. https://www.columbiamissourian.com/news/higher_education/racial-climate-atmu-a-timeline-of-incidents-in-fall-2015/article_0c96f986-84c6-11e5-a38f2bd0aab0bf74.html.

Vandiver, B. J., Cross Jr, W. E., Worrell, F. C., \& Fhagen-Smith, P. E. (2002). Validating the Cross Racial Identity Scale. Journal of Counseling psychology, 49(1), 71.

Vuong, M., Brown-Welty, S., \& Tracz, S. (2010). The effects of self-efficacy on academic success of first-generation college sophomore students. Journal of college student development, 51(1), 50-64.

White House. (2014). My brother's keeper task force report to the President. The White House. Retrieved from https://www.whitehouse.gov/my-brothers-keeper\# 
Willms, J. D. (2000). Monitoring school performance for standards-based reform'. Evaluation \& Research in Education, 14(3-4), 237-253.

Wilson, W. J. (2008). More than just race: Being black and poor in the inner city (issues of our time). WW Norton \& Company.

Worrell, F. C., Cross Jr, W. E., \& Vandiver, B. J. (2001). Nigrescence theory: Current status and challenges for the future. Journal of multicultural counseling and development, 29(3), 201-213.

Yazan, B. (2015). Three approaches to case study methods in education: Yin, Merriam, and Stake. The qualitative report, 20(2), 134-152.

Yin, R. K. (1992). The case study method as a tool for doing evaluation. Current sociology, 40(1), 121-137. 
APPENDIX

Table 1

Within-Group Differences: Interpersonal Variables

\begin{tabular}{|c|c|c|c|c|c|c|c|c|c|}
\hline \multirow{2}{*}{\multicolumn{2}{|c|}{$\begin{array}{l}\text { Treatment } \\
(n=9)\end{array}$}} & \multicolumn{2}{|c|}{$\begin{array}{l}\text { University } \\
\text { Belonging }\end{array}$} & \multicolumn{2}{|c|}{ CSEI } & \multicolumn{2}{|c|}{ CDMSE } & \multicolumn{2}{|c|}{$\begin{array}{l}\text { University } \\
\text { Mattering }\end{array}$} \\
\hline & & $M$ & $S D$ & $M$ & $S D$ & $M$ & $S D$ & $M$ & $S D$ \\
\hline & Pre & 76 & 3.64 & 112.75 & 20.03 & 92.57 & 13.68 & 69.25 & 3.84 \\
\hline & Mid & 78.11 & 5.06 & 114.37 & 29.72 & 95 & 18.51 & 68.12 & 6.62 \\
\hline & Post & 78.77 & 5.82 & 123.12 & 20.5 & 100.85 & 14.53 & 68.12 & 2.23 \\
\hline & $d$ & \multicolumn{2}{|c|}{.57} & \multicolumn{2}{|c|}{.51} & \multicolumn{2}{|c|}{.58} & \multicolumn{2}{|c|}{.36} \\
\hline \multicolumn{10}{|l|}{$\begin{array}{l}\text { Control } \\
(n=4)\end{array}$} \\
\hline & Pre & 80.25 & 9.46 & 101.25 & 24.27 & 102 & 3.46 & 73.5 & 2.38 \\
\hline & Mid & 82 & 9.12 & 96 & 13.9 & 92 & 4.83 & 76.25 & 13.52 \\
\hline & Post & 79.75 & 8.65 & 102.75 & 23.4 & 98.75 & 10.56 & 75 & 5.88 \\
\hline & $d$ & \multicolumn{2}{|c|}{.05} & \multicolumn{2}{|c|}{.06} & \multicolumn{2}{|c|}{.41} & \multicolumn{2}{|c|}{.33} \\
\hline
\end{tabular}

Table 2

Within-Group Differences: Racial Identity

Multicultural

\begin{tabular}{|c|c|c|c|c|c|c|c|c|c|c|c|c|}
\hline$=9)$ & $M$ & $S D$ & $M$ & $S D$ & $M$ & $S D$ & $M$ & $S D$ & $M$ & $S D$ & $M$ & $S D$ \\
\hline Pre & 17.55 & 8.38 & 16.33 & 4.74 & 10.11 & 4.19 & 28.89 & 3.75 & 8.55 & 2.29 & 17.44 & 5.1 \\
\hline Mid & 15.55 & 7.78 & 14.78 & 4.05 & 8.44 & 4.50 & 30.11 & 2.80 & 9.67 & 3.28 & 15.22 & \\
\hline Post & 15.33 & 8.48 & 10.67 & 2.29 & 7.11 & 2.20 & 30.22 & 2.54 & 8.11 & 2.97 & 14.77 & \\
\hline$d$ & \multicolumn{2}{|c|}{.26} & \multicolumn{2}{|c|}{1.52} & \multicolumn{2}{|c|}{.89} & \multicolumn{2}{|c|}{.42} & & \multicolumn{2}{|c|}{.53} \\
\hline
\end{tabular}

Control

$(n=4)$

\begin{tabular}{rcccccccccccc} 
Pre & 21.25 & 10.75 & 14 & 2.71 & 12 & 8.45 & 33.50 & 1.73 & 8.50 & 2.29 & 15.75 & 7.41 \\
Mid & 16 & 7.41 & 13.75 & 1.5 & 10.15 & 5.85 & 34.25 & 0.96 & 6.75 & 2.87 & 13.25 & 5.31 \\
Post & 15.75 & 4.78 & 11.5 & 1.29 & 11.75 & 4.92 & 33.5 & 3 & 7.5 & 3.69 & 12.25 & 5.19 \\
$d$ & \multicolumn{6}{c}{.66} & \multicolumn{2}{c}{1.17} & \multicolumn{2}{c}{.25} & 0 & \multicolumn{2}{c}{.32} & & .54
\end{tabular}




\section{Table 3}

Between-Group Differences: Interpersonal Variables

\begin{tabular}{|c|c|c|c|c|c|c|c|c|}
\hline \multirow{3}{*}{$\begin{array}{l}\text { Treatment } \\
(n=9)\end{array}$} & \multicolumn{2}{|c|}{$\begin{array}{l}\text { University } \\
\text { Belonging }\end{array}$} & \multicolumn{2}{|c|}{ CSEI } & \multicolumn{2}{|c|}{ CDMSE } & \multicolumn{2}{|c|}{$\begin{array}{l}\text { University } \\
\text { Mattering }\end{array}$} \\
\hline & $M$ & $S D$ & $M$ & $S D$ & $M$ & $S D$ & $M$ & $S D$ \\
\hline & 78.77 & 5.82 & 123.12 & 20.5 & 100.85 & 14.53 & 68.12 & 2.23 \\
\hline
\end{tabular}

Control $(n=4)$

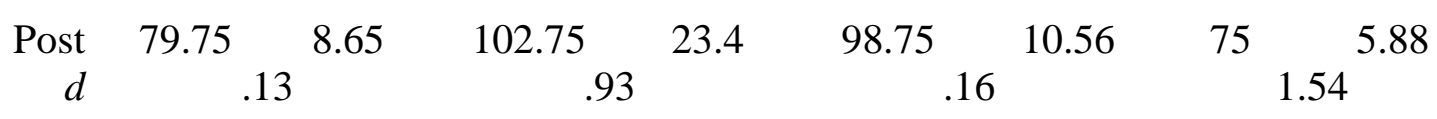

\section{Table 4}

Between-Group Differences: Racial Identity

\begin{tabular}{|c|c|c|c|c|c|c|c|c|c|c|c|c|}
\hline \multirow{2}{*}{$\begin{array}{l}\text { Treatment } \\
(n=9)\end{array}$} & \multicolumn{2}{|c|}{ Assimilation } & \multicolumn{2}{|c|}{ Miseducation } & \multicolumn{2}{|c|}{ Self-Hatred } & \multicolumn{2}{|c|}{$\begin{array}{l}\text { Multicultural } \\
\text { Inclusive }\end{array}$} & \multicolumn{2}{|c|}{ Anti-White } & \multicolumn{2}{|c|}{ Afrocentricity } \\
\hline & $M$ & & $M$ & $S D$ & $M$ & $S D$ & $M$ & $S D$ & $M$ & $S D$ & $M$ & $S D$ \\
\hline Post & 15.33 & 8.48 & 10.67 & 2.29 & 7.11 & 2.20 & 30.22 & 2.54 & 8.11 & 2.97 & 14.77 & 4.8 \\
\hline
\end{tabular}

Control

$(n=4)$

$\begin{array}{rcccccccccccc}\text { Post } & 15.75 & 4.78 & 11.5 & 1.29 & 11.75 & 4.92 & 33.5 & 3 & 7.5 & 3.69 & 12.25 & 5.19 \\ d & .06 & .45 & 1.36 & 1.18 & .18 & .50\end{array}$


Table 5

Qualitative Participants

\begin{tabular}{llllll} 
Alias & Group & Age & Major & $\begin{array}{l}\text { Sexual } \\
\text { Orientation }\end{array}$ & $\begin{array}{l}\text { Religious } \\
\text { Affiliation }\end{array}$ \\
\hline Eli Shane & Treatment & 18 & Chemical Engineering & Heterosexual & Other \\
Jet & Treatment & 18 & Radio/Television Journalism & Heterosexual & Christian \\
Matthew & Treatment & 18 & Biological Science & Heterosexual & Christian \\
Ray & Treatment & 19 & International Business & Heterosexual & Nothing in \\
Nathaniel & Treatment & 18 & Mechanical Engineering & Heterosexual & Christian \\
MoFeezy & Treatment & 18 & Computer and Electrical & Heterosexual & Christian \\
& & & Engineering & & \\
Wayne & Control & 18 & Journalism & Homosexual & Christian \\
Udo & Control & 18 & Computer Engineering & Heterosexual & Atheist \\
Brian & Control & 18 & Finance & Bisexual & Agnostic
\end{tabular}


Table 6

Qualitative Themes

Superordinate Subthemes $\quad$ Quotes
Themes

COVID-19 Academic Adjustment

when I first got here, it was just, "Oh, I can worry about schoo a little bit later since it's online and everything," like, "I'm just going to watch a lot of TV and play video games." So then after that, I was just like, "If I wait until the last minute--," because one of my classes, all his stuff was due-- all the testing and things was due on May 8th. I was just like, "If I wait to the last minute, I'm just going to be more stressed-out than what I need to be." So that's when I decided to start picking up the pace, being productive in school. - Eli Shane

\section{Missed Opportunities}

Safety Concerns

Access

Support

Involvement

Socio-Cultural Capital

Identity Development
Well, it cut off my whole second semester of college. So there was that. Obviously, it cut my year short, and then everybody moved off-campus. So there is nobody here to hang out with or get to know, and everything moved online, and that was a bit difficult for me - Brian

my dad hasn't been working for a while now, but I think he goes back by 18 th, I think. I don't know for certain. My mom, while she's still working right now, she just got notified that she will be getting laid off. So she thinks that's coming up sometime around June. It's when that's going to happen. Luckily, I have a job opportunity for over the summer that will be paying a decent amount, and if it comes down to and I need to help provide them, I will be making enough to do so. - MoFeezy

I think the leadership [BMI director] and the mentor team was really important in [BMI]. I think I had a good relationship with all of them, especially my own peer mentor. I think they were important in just helping us as well, having somebody that we could talk to, somebody that's been in our shoes as freshmen, and now they're sophomores. - Jet

I would say I try to be pretty involved with things. Well, not overstressing myself, but [I was in ASA Actually, I remember for the LBC, Homecoming Court, Legion of Black Collegians, that was something that kind of-- that was just me trying to get out of my comfort zone and trying to put myself out there. That was a really good experience. I also met the people in that court that I wouldn't have met otherwise, that I probably wouldn't have talked to otherwise. And then I'm in MAPS, Minority Association for Pre-Med, I believe. MAPS, yeah. So that helped me because, again, the people in there, they're all trying to go to medical school, go to the medical field. - Matthew

So with [BMI], well, first things first is if it wasn't for [BMI] I wouldn't be friends with the majority of my [BMI] brothers. - Eli Shane

being a part of a black community and being around like so many pro-black people, I guess, which isn't a big thing where I come from, was like really positive to me and how I see myself and how I see other black people, too - Brian

\section{Formal Education}

I got to $[\mathrm{BMI}]$ and it was different because I had gone through the syllabus, read it, and it was, this all seems like stuff that I have already learned...... It's like when you know of something that impacts you, you should know probably the most about it. And I didn't realize that until [BMI] started those conversations - Ray

\author{
Intersectionality
}

in $[\mathrm{BMI}]$, there is a lot of topics that we talked about that I never really went into detail with. It was, like, masculinity, talking about that a lot. But yeah. That was something that I really kind of ran with - Matthew 
Interview Protocol

Thank you for completing each survey throughout the year. The purpose of this study was to capture the impact of MBMI on the first-year experience of black men at MU. Based on the results of the survey, we have developed a series of questions that we hope will provide further context and explanation to our findings.

1. First, I imagine that the global pandemic of COVID-19 has impacted you to some degree. How are you and your family doing?

2. Tell me about your first year of college.

1. What were your expectations? Expectations of MU?

2. How would you say the coronavirus impacted your experience?

3. What events stood out to you throughout the year? Why?

4. What was it like being a Black man on campus?

5. What was your experience with MBMI?

1. How would you describe your MBMI cohort?

2. Describe your relationship with your cohort/leadership team/MU campus/Columbia community.

3. What MBMI events stand out to you? Why?

6. How would you describe your involvement on campus?

1. Number/type of organization(s)

7. Results indicated that in the first semester, MBMI students made minor increases in their Sense of Belonging, College Self Efficacy, and Career Decision Making. How do these results fit with your experience?

8. MBMI students also seemed to feel like they mattered less after their first semester. Can you talk about your experience and feeling like you mattered? 
1. On campus?

2. To MBMI?

9. What impact, if any did MBMI have on your sense of...

1. Belonging to the $\mathrm{MU}$

2. Feeling like you mattered at MU

3. Your confidence in completing college level tasks

4. Your confidence to navigate career decision making

10. The results also indicate that in the first semester, there was no significant difference between MBMI students and non MBMI Black male students in the same categories mentioned earlier (University Belonging, Mattering, College Self Efficacy, and Career Decision Making).

1. Based on your experience, what was the difference between your experience and Black men who were not in MBMI?

2. Is there something available to non-MBMI Black men that can be an alternative to MBMI?

11. At the beginning of the semester your cohort averaged high scores on the SelfHatred and Anti-White stages of racial development. The same two were the highest for the second survey as well. How does this fit with your experience?

1. How did you see your own racial identity developing throughout the year?

12. What would you like us to know about your experience as a first-year student at MU and as a member of this year's MBMI cohort? 
VITA

Jonathan Ferguson is a doctoral candidate in the Counseling Psychology doctoral program at the University of Missouri-Columbia and is currently completing his internship in the Clinical Assessment and Diagnostic department at Emory University School of Medicine's Marcus Autism Center. He is originally from Miami, Florida and enrolled in the doctoral program at Mizzou after briefly working in the Atlanta, Georgia area. Previous educational experiences include a bachelor's degree in psychology and master's degree in community psychology, both from Florida A\&M University. Jonathan's research focuses largely on Black male development and belongingness. Specifically, he is interested in understanding the development of masculinity for Black males and how their sense of belonging in different spaces impacts their development (e.g., identity, masculinity, self-perception, academic progress, career development, etc.). His clinical work is centered around pediatric psychological evaluation and diagnosis of Autism Spectrum Disorder and other neurodevelopmental disorders. Jonathan also has a passion for working in and servicing communities of color through advocacy, mentoring, group facilitation, and representation. 